\title{
Root and Root Canal Morphology Differences Between Genders: A Comprehensive in-vivo CBCT Study in a Saudi Population
}

\section{Razlike u broju i morofologiji korijena i korijenskih kanala među spolovima: sveobuhvatno istraživanje in-vivo primjenom CBCT-a na populaciji Saudijske Arabije}

\author{
${ }^{1}$ Department of Restorative Dental Sciences, College of Dentistry, Jazan University, Jazan, Kingdom of Saudi Arabia. \\ Zavod za restauracije u dentanoj medicini Stomatološkog fakulteta Sveučilišta u Jazanu, Jazan, Kraljevina Saudijska Arabija \\ 2 Department of Restorative Dentistry and Endodontics, Sapienza University of Rome, Rome, Italy. \\ Zavod za restaurativnu stomatologiju i endodonciju Sveučilišta Sapienza u Rimu, Rim, Italija
}

\section{Abstract}

Objectives: To comprehensively explore the differences of all maxillary and mandibular permanent teeth in relation to number of roots, number of root canals, and root canal configuration between both genders in a Saudi Arabian population. Methods: This retrospective radiographic study comprised 208 subjects ( $48 \%$ males and $52 \%$ females) with a mean age $28.74 \pm 9.56$ years. The CBCT images of the recruited subjects were evaluated for all permanent teeth. A careful examination was obtained by optimal visualization using all the software features. The data were analyzed using SPSS software program. Cohen's Kappa test was used for reliability and the Chi-squared test of association was used for the differences between both genders in relation to the study variables. A P-value < 0.05 was considered significant. Results: A total of 5254 maxillary and mandibular permanent teeth were evaluated. In relation to number of roots, there were no significant differences between both genders for all maxillary and mandibular teeth together $(P=0.064)$ as well as for maxillary and mandibular teeth separately $(P=0.315$ and $P=0.100$, respectively). A significant difference was found between males and females in relation to the number of canals of maxillary teeth $(P=0.014)$. For mandibular teeth, the significant level of difference was at the cut-off point $(P=0.050)$. For all maxillary and mandibular teeth together, the distribution among both genders was not significant $(P=0.082)$. The difference between both genders with regard to canal configuration of maxillary roots was highly statistically significant $(P<0.001)$. For mandibular teeth, the difference between males and females in relation canal configuration of anterior and premolar teeth was significant $(P=0.016)$ while, the difference was not significant when related to mesial roots of $1^{\text {st }}$ and $2^{\text {nd }}$ molars $(P=0.205)$. However, the difference was highly significant when related to distal roots of $1^{\text {tt }}$ and $2^{\text {nd }}$ molars $(P<0.001)$. Conclusion: No significant differences between both genders in relation to number of roots were found. Regarding the number of canals, significant differences were found only in three groups out of 14 groups of teeth with females who had a smaller number of canals than males. For canal configuration, two groups of maxillary teeth and three groups of mandibular teeth showed statistically significant differences between both genders.
Received: May 24, 2019

Accepted: July 27, 2019

Address for correspondence

Mohammed Mashyakhy

Department of Restorative Dental Sciences

College of Dentistry, Jazan University Jazan, Kingdom of Saudi Arabia, P.O Box 114

dr.mashyakhy@gmail.com

Key words

Tooth root; Dental Pulp Cavity; Dental Anatomy

\section{Introduction}

Differences between genders regarding some anatomical variations (1), and the incidence and behavior of diseases are well documented in medicine $(2-5)$ as well as in dentistry the differences between males and females regarding root morphology $(6,7)$ and the association with some diseases were also reported $(8,9)$. In the dental literature, many anatomical studies addressed different variations in root canal morphology according to ethnic background (10-18), while, scarce and inconclusive information are available regarding gender
Uvod

Razlike između spolova s obzirom na neke anatomske varijacije (1), zatim učestalost i tijek bolesti dobro su dokumentirani u općoj medicini $(2-5)$, pa tako i u dentalnoj medicini postoje razlike između muškaraca i žena kad je riječ o morfologiji korijena zuba $(6,7)$ i o povezanosti s nekim bolestima $(8,9)$. U stomatološkoj literaturi autori mnogih anatomskih istraživanja bavili su se različitim varijacijama morfologije korijenskih kanala prema etničkoj pripadnosti $(10$ - 18), a dostupne su također rijetke i nedostatne informacije o utjecaju 
impact on teeth morphology $(19,20)$. The first in-vitro study reported the gender differences in all groups of teeth in the same patients was published in 2004 by Sert and Bayirli in a Turkish population (20). The authors used clearing and dye technique, and concluded that gender needs to be considered carefully when performing the preoperative evaluation of nonsurgical endodontic treatment.

Upon conducting a literature search, there were only two published in-vivo studies which addressed the association of gender with number of roots and root canal system (RCS) in all groups of teeth. The first comprehensive in-vivo cone-beam computed tomography (CBCT) study on a Portuguese population was published in 2018 with a large sample size (19) showed that few differences were present between genders. The other in-vivo CBCT study was published in 2019, dealing with a Malaysian subpopulation (21). It was reported that in general there were no significant differences between genders apart from few groups of teeth. Few in-vivo CBCT anatomical studies on different populations addressed the differences between genders in specific groups of teeth $(7,22-25)$. However, those studies did not give a complete picture of the influence of gender on teeth morphology. In addition, only few in-vivo CBCT anatomical studies were performed on a Saudi Arabian population which addressed gender differences in some groups of teeth (26-30). The results of those studies varied widely among different groups of teeth in favor of males or females while some teeth showed no significant differences.

Since the majority of the studies were not comprehensive $(6,21,22-30)$, the information retrieved are too fragmented and not conclusive, although some studies $(7,24)$ had a relatively large sample size for a specific group of teeth. The aim of the present in-vivo CBCT study, therefore, was to comprehensively evaluate the influence of gender on all permanent teeth morphology in a Saudi Arabian population, with a null hypothesis: no differences between genders with regard to root numbers, root canal numbers and root canal configurations.

\section{Methodology}

\section{The sample}

A total of 208 patients (100 (48\%) males and 108 (52\%) females) with mean age $28.74 \pm 9.56$ years (median $=26$ years) ranging from 17 to 59 years were included in this study. From them, 5223 maxillary and mandibular permanent teeth were evaluated. The CBCT scans were retrieved from the database of College of Dentistry, Jazan University, Jazan, Saudi Arabia from the period from 2016 to 2018. The study protocol was approved by the local institutional review board. The teeth with fully developed roots and closed apices were included in the study. Previously treated-root canal or root canal treatment-initiated teeth; teeth with periapical lesions, calcification or resorption, and distorted $\mathrm{CBCT}$ images were excluded.

\section{CBCT scans}

The CBCT machine used in this retrospective cross-sectional in-vivo study was 3D Accuitomo 170 (MORITA, Japan) and the scanning parameters were constant for all patients as follows: FOV 170-120 mm, $90 \mathrm{Kv}, 5-8 \mathrm{~mA}, 17.5$ seconds exposure time and $0.25 \mathrm{~mm}$ voxel size. All CBCT spola na morfologiju zuba $(19,20)$. Prvo istraživanje in vitro o spolnim razlikama u svim skupinama zuba istih pacijenata u turskoj populaciji objavili su Sert i Bayirli 2004. godine (20). Autori su se koristili tehnikom čišćenja i bojenja te zaključili da je potrebno uzeti u obzir spol pri predoperativnoj procjeni tijekom nekirurškoga endodontskog liječenja.

Nakon pretraživanja literature pronađena su samo dva objavljena istraživanja in vivo o povezanosti spola s brojem korijena i sustavom korijenskih kanala (RCS) u svim skupinama zuba. Prvo sveobuhvatno istraživanje in vivo na temelju CBCT dijagnostike provedeno na velikom uzorku portugalske populacije i objavljeno je 2018. (19), a pokazalo je da je bilo malo razlika između spolova. Drugo takvo istraživanje objavljeno je 2019., a odnosilo se na malezijsku subpopulaciju (21). Navedeno je da općenito nema značajnih razlika između spolova, osim na nekoliko skupina zuba. Nekoliko anatomskih istraživanja in vivo s pomoću CBCT-a na različitim populacijama riješilo je razlike između spolova u određenim skupinama zuba $(7,22-25)$. No u tim istraživanjima nije dana potpuna slika utjecaja spola na morfologiju zuba. Uz to, samo je nekoliko anatomskih istraživanja in vivo s primjenom CBCT-a provedeno na populaciji Saudijske Arabije i bavila su se spolnim razlikama na nekim skupinama zuba $(26$ - 30). Rezultati tih istraživanja uvelike su varirali kad je riječ o različitim skupinama zuba u korist muškaraca ili žena, a na nekim zubima nisu uočene značajne razlike.

Budući da većina istraživanja nije bila sveobuhvatna $(6$, $21,22-30)$, dobiveni podatci previše su fragmentirani i nepouzdani, iako je u nekim istraživanjima $(7,24)$ bio razmjerno velik uzorak za određenu skupinu zuba. Zato je cilj ovog istraživanja in vivo primjenom CBCT-a bio sveobuhvatno procijeniti utjecaj spola na morfologiju svih trajnih zuba u populaciji Saudijske Arabije, uz nultu hipotezu da nema razlike među spolovima s obzirom na broj korijena, broj korijenskih kanala i konfiguraciju korijenskih kanala.

\section{Ispitanici i metode}

\section{Uzorak}

U ovo istraživanje bilo je uključeno 208 sudionika (100/48 \% muškaraca i 108/52 \% žena) prosječne dobi $28,74 \pm 9,56$ godina (medijan $=26$ godina) u rasponu od 17 do 59 godina. Analizirana su 5223 gornja i donja trajna zuba. CBCT skenovi preuzeti su iz baze Stomatološkog fakulteta Sveučilišta u Jazanu (Jazan, Saudijska Arabija), u razdoblju od 2016. do 2018. Protokol istraživanja odobrio je lokalni institucionalni etički odbor. $U$ istraživanje su uključeni zubi $s$ potpuno razvijenim korijenima i zatvorenim apeksima. $\mathrm{Ni}$ su bili uključeni endodontski liječeni zubi ili zubi sa započetim liječenjem, zubi s periapikalnim lezijama, kalcifikacijom ili resorpcijom te izobličene $\mathrm{CBCT}$ snimke.

\section{CBCT snimke}

CBCT uređaj koji se koristio u ovom retrospektivnom presječnom istraživanju in vivo bio je $3 \mathrm{D}$ Accuitomo 170 (MORITA, Japan), a parametri skeniranja bili su konstantni za sve pacijente kako slijedi: FOV $170-120 \mathrm{~mm}, 90 \mathrm{Kv}$, 5-8 mA, vrijeme ekspozicije 17,5 sekunda i veličina vokse- 
images were processed and reconstructed using Morita's iDixel 3D imaging software. Serial axial, coronal and sagittal sections were acquired to evaluate the number of roots, the number of the canals and RCS configurations on the basis of Vertucci's classification. A careful examination was obtained by optimal visualization using all the software features, such as zooming, change in contrast and brightness. For reliability testing, the main author evaluated $20 \%$ of the sample twice within 4 weeks interval period.

\section{Data analysis}

The collected data were introduced to the Statistical Package of Social Sciences software program for Windows (SPSS V25; IBM, Chicago, IL), and were subsequently coded and analyzed. The number of roots, the number of canals and canal system configurations of all permanent teeth apart from the third molars were evaluated. The differences by gender were assessed for the above-mentioned variables. The results were expressed as frequencies and percentages. The Chisquared test was used for finding the differences between both genders. Kappa test was also used for intra-rater reliability. The level of significance for all statistical tests was set at $\mathrm{P}$-value $<0.05$.

\section{Results}

Cohen's kappa test revealed an agreement of measurement with the value of 0.85 and $\mathrm{P}<0.001$.

\section{Maxillary and mandibular teeth}

In general, there were no significant differences between both genders in relation to the number of roots of maxillary and mandibular teeth separately $(\mathrm{P}=0.315$ and $\mathrm{P}=0.100$, respectively). Also, no significant differences were found for all maxillary and mandibular teeth together $(\mathrm{P}=0.064)$. However, a significant difference was found between males and females in relation to the number of canals of maxillary teeth $(\mathrm{P}=0.014)$ where the teeth with 1 or 3 canals were found more frequently in females than in males, while the teeth with 2 or 4 canals were found more frequently in males than in females. For mandibular teeth, the significant level of difference between males and females in relation to the number of canals was at the cut-off point $(\mathrm{P}=0.050)$. For all maxillary and mandibular teeth together, the distribution among both genders in relation to the number of canals was not significant $(\mathrm{P}=0.082)$ (Table 1) (Figure 1 and Figure 2).

The difference between both genders with regard to canal configuration of maxillary roots was highly statistically significant $(\mathrm{P}<0.001)$. The roots with Vertucci type I, III, and V were more frequently found in females than in males while, the roots with Vertucci type II, IV, VI, and VII were more frequently found in males than in females. For mandibular teeth, the difference between males and females in relation to the canal configuration of anterior and premolar teeth was significant $(\mathrm{P}=0.016)$, while the difference was not significant when related to the canal configuration of mesial roots of the first and the second $(\mathrm{P}=0.205)$. However, the difference between males and females was highly significant when related to canal configuration of distal roots of the first and the second molars together $(\mathrm{P}<0.001)$ (Table 2) (Figures 3 and 4$)$. la $0,25 \mathrm{~mm}$. Sve CBCT snimke obrađene su i rekonstruirane s pomoću softvera za obradu slika Moritinog i-Dixel 3D. Serijski aksijalni, koronalni i sagitalni presjeci dobiveni su za procjenu broja korijena, broja i konfiguracija kanala na temelju Vertuccijeve klasifikacije. Detaljan pregled dobiven je optimalnom vizualizacijom s pomoću svih softverskih značajki, poput zumiranja, promjene kontrasta i svjetline. Za ispitivanje pouzdanosti glavni je autor dva puta u roku od četiri tjedna procjenjivao $20 \%$ uzoraka.

\section{Analiza podataka}

Prikupljeni podatci uvedeni su u program Statistical Package of Social Sciences (statistički paket za društvene znanosti) za Windowse (SPSS V25; IBM, Chicago, IL), a zatim su kodirani i analizirani. Procijenjeni su broj korijena, broj kanala i konfiguracija kanalnog sustava svih trajnih zuba, osim trećih kutnjaka. Razlike prema spolu procijenjene su za sve navedene varijable. Rezultati su izraženi u frekvencijama i postotcima. Za ispitivanje razlika između spolova primijenjen je Chi-kvadrat test. Kappa test također je upotrebljen za pouzdanost unutar ispitivača. Razina značajnosti za sve statističke testove postavljena je na $\mathrm{P}<0,05$.

\section{Rezultati}

Cohenov Kappa test otkrio je podudarnost mjerenja s vrijednošću od 0,85 i $\mathrm{P}<0,001$.

Gornji i donji zubi

Općenito nije bilo značajnih razlika između spolova u odnosu prema broju korijena gornjih i donjih zuba zasebno ( $\mathrm{P}$ $=0,315 \mathrm{i} \mathrm{P}=0,100)$. Također nisu pronađene značajne razlike za sve gornje i donje zube zajedno $(\mathrm{P}=0,064)$. No utvrđena je značajna razlika između muškaraca i žena u odnosu prema broju kanala gornjih zuba $(P=0,014)$ - zubi $s$ jednim kanalom ili trima kanalima nađeni su češće kod žena negoli kod muškaraca, a zubi s dvama ili četirima kanalima bili su češći kod muškaraca negoli kod žena. Za donje zube značajnost razlike između muškaraca i žena u odnosu prema broju kanala bila je na granici $(P=0,050)$. Za sve gornje i donje zube zajedno, distribucija između spolova u odnosu prema broju kanala nije bila statistički značajna $(P=0,082)$ (tablica 1.) (slike 1. i 2.).

Razlika između spolova, $s$ obzirom na konfiguraciju korijenskih kanala gornjih zuba, bila je visoko statistički značajna $(\mathrm{P}<0,001)$. Korijeni s tipovima I, III i V prema Vertucciju češce su pronađeni kod žena negoli kod muškaraca, a korijeni s tipovima II, IV, VI i VII bili su češći kod muškaraca negoli kod žena. Za donje zube razlika između muškaraca i žena u odnosu prema konfiguraciji kanala prednjih zuba i pretkutnjaka bila je značajna $(P=0,016)$, a razlika nije bila značajna $\mathrm{u}$ vezi $s$ konfiguracijom kanala mezijalnih korijena prvoga $\mathrm{i}$ drugoga kutnjaka $(P=0,205)$. No razlika između muškaraca i žena bila je visoko značajna s obzirom na konfiguraciju kanala distalnih korijena prvoga i drugoga kutnjaka zajedno ( $\mathrm{P}$ $<0,001$ ) (tablica 2.) (slike 3. i 4.). 
Table 1 Distribution of maxillary teeth, mandibular teeth, and all maxillary and mandibular teeth together among both genders according to number of roots and number of canals

Tablica 1. Distribucija gornjih zuba, donjih zuba i svih gornjih i donjih zuba zajedno među spolovima prema broju korijena i kanala

\begin{tabular}{|c|c|c|c|c|c|c|c|c|c|c|c|c|c|}
\hline & & \multicolumn{4}{|c|}{ Upper teeth • Gornji zubi } & \multicolumn{4}{|c|}{ Lower teeth $\bullet$ Donji zubi } & \multicolumn{4}{|c|}{ All teeth $\bullet$ Svi zubi } \\
\hline & & M & $\mathrm{F} \cdot \check{\mathrm{Z}}$ & $\begin{array}{l}\text { Total • } \\
\text { Ukupno }\end{array}$ & $\mathbf{P}$ & M & $\mathrm{F} \bullet \check{\mathrm{Z}}$ & $\begin{array}{l}\text { Total • } \\
\text { Ukupno }\end{array}$ & $\mathbf{P}$ & M & $\mathrm{F} \bullet \check{Z}$ & $\begin{array}{c}\text { Total • } \\
\text { Ukupno }\end{array}$ & $\mathbf{P}$ \\
\hline \multirow{3}{*}{ 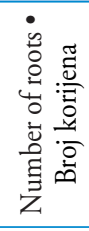 } & 1 root $\cdot 1$ korijen & $\begin{array}{c}777 \\
(64.4) \\
\end{array}$ & $\begin{array}{c}836 \\
(65.3) \\
\end{array}$ & $\begin{array}{c}1613 \\
(64.9) \\
\end{array}$ & \multirow{4}{*}{0.315} & $\begin{array}{c}962 \\
(74.5) \\
\end{array}$ & $\begin{array}{c}1033 \\
(76.9) \\
\end{array}$ & $\begin{array}{c}1995 \\
(75.7) \\
\end{array}$ & \multirow{4}{*}{0.100} & $\begin{array}{r}1739 \\
(69.6) \\
\end{array}$ & $\begin{array}{c}1869 \\
(71.2) \\
\end{array}$ & $\begin{array}{l}3608 \\
(70.5) \\
\end{array}$ & \multirow{4}{*}{0.064} \\
\hline & 2 roots $\cdot 2$ korijena & $\begin{array}{c}130 \\
(10.8) \\
\end{array}$ & $\begin{array}{c}115 \\
(9.0) \\
\end{array}$ & $245(9.9)$ & & $\begin{array}{c}321 \\
(24.5) \\
\end{array}$ & $\begin{array}{c}296 \\
(22.0) \\
\end{array}$ & $\begin{array}{c}617 \\
(23.4) \\
\end{array}$ & & $\begin{array}{c}451 \\
(18.1) \\
\end{array}$ & $\begin{array}{c}411 \\
(15.7) \\
\end{array}$ & $\begin{array}{c}862 \\
(16.8) \\
\end{array}$ & \\
\hline & 3 roots $\bullet 3$ korijena & $\begin{array}{c}299 \\
(24.8)\end{array}$ & $\begin{array}{c}329 \\
(25.7)\end{array}$ & $\begin{array}{c}628 \\
(25.3)\end{array}$ & & $\begin{array}{c}8 \\
(0.6)\end{array}$ & $\begin{array}{c}15 \\
(1.1)\end{array}$ & $23(0.9)$ & & $\begin{array}{c}307 \\
(12.3)\end{array}$ & $\begin{array}{c}344 \\
(13.1)\end{array}$ & $\begin{array}{c}651 \\
(12.7)\end{array}$ & \\
\hline \multicolumn{2}{|c|}{ Total • Ukupno } & $\begin{array}{r}1206 \\
(48.5) \\
\end{array}$ & $\begin{array}{r}1280 \\
(51.5) \\
\end{array}$ & $\begin{array}{c}2486 \\
(100.0)\end{array}$ & & $\begin{array}{c}1291 \\
(49.0)\end{array}$ & $\begin{array}{r}1344 \\
(51.0) \\
\end{array}$ & $\begin{array}{c}2635 \\
(100.0) \\
\end{array}$ & & $\begin{array}{l}2497 \\
(48.8) \\
\end{array}$ & $\begin{array}{c}2624 \\
(51.2) \\
\end{array}$ & $\begin{array}{c}5121 \\
(100.0) \\
\end{array}$ & \\
\hline \multirow{4}{*}{ 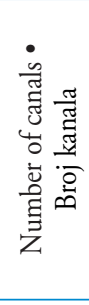 } & 1 canal $\bullet 1$ kanal & $\begin{array}{c}621 \\
(51.5) \\
\end{array}$ & $\begin{array}{c}679 \\
(53.0) \\
\end{array}$ & $\begin{array}{c}1300 \\
(52.3) \\
\end{array}$ & \multirow{5}{*}{$0.014^{*}$} & $\begin{array}{c}751 \\
(58.2)\end{array}$ & $\begin{array}{c}851 \\
(63.3) \\
\end{array}$ & $\begin{array}{c}1602 \\
(60.8) \\
\end{array}$ & \multirow{5}{*}{0.050} & $\begin{array}{c}1372 \\
(54.9) \\
\end{array}$ & $\begin{array}{c}1530 \\
(58.3)\end{array}$ & $\begin{array}{c}2902 \\
(56.7) \\
\end{array}$ & \multirow{5}{*}{0.082} \\
\hline & 2 canals $\bullet 2$ kanala & $\begin{array}{c}283 \\
(23.5)\end{array}$ & $\begin{array}{c}268 \\
(20.9)\end{array}$ & $\begin{array}{c}551 \\
(22.2)\end{array}$ & & $\begin{array}{c}220 \\
(17.0)\end{array}$ & $\begin{array}{c}203 \\
(15.1)\end{array}$ & $\begin{array}{c}423 \\
(16.1)\end{array}$ & & $\begin{array}{c}503 \\
(20.1)\end{array}$ & \begin{tabular}{|c|}
471 \\
$(17.9)$ \\
\end{tabular} & $\begin{array}{c}974 \\
(19.0)\end{array}$ & \\
\hline & 3 canals $\bullet 3$ kanala & $\begin{array}{c}59 \\
(4.9)\end{array}$ & $\begin{array}{c}98 \\
(7.7)\end{array}$ & $157(6.3)$ & & $\begin{array}{c}260 \\
(20.1)\end{array}$ & $\begin{array}{c}229 \\
(17.0) \\
\end{array}$ & $\begin{array}{c}489 \\
(18.6) \\
\end{array}$ & & $\begin{array}{c}319 \\
(12.8)\end{array}$ & $\begin{array}{c}327 \\
(12.5) \\
\end{array}$ & $\begin{array}{c}646 \\
(12.6) \\
\end{array}$ & \\
\hline & 4 canals $\bullet 4$ kanala & $\begin{array}{c}243 \\
(20.1) \\
\end{array}$ & $\begin{array}{c}235 \\
(18.4)\end{array}$ & $\begin{array}{c}478 \\
(19.2)\end{array}$ & & $\begin{array}{c}60 \\
(4.6)\end{array}$ & $\begin{array}{c}61 \\
(4.5)\end{array}$ & 121 (4.6) & & $\begin{array}{c}303 \\
(12.1)\end{array}$ & $\begin{array}{c}296 \\
(11.3) \\
\end{array}$ & $\begin{array}{c}599 \\
(11.7)\end{array}$ & \\
\hline \multicolumn{2}{|c|}{ Total $\bullet$ Ukupno } & $\begin{array}{c}1206 \\
(48.5)\end{array}$ & $\begin{array}{l}1280 \\
(51.5)\end{array}$ & $\begin{array}{c}2486 \\
(100.0)\end{array}$ & & $\begin{array}{c}1291 \\
(49.0)\end{array}$ & $\begin{array}{c}1344 \\
(51.0)\end{array}$ & $\begin{array}{c}2635 \\
(100.0)\end{array}$ & & $\begin{array}{l}2497 \\
(48.8)\end{array}$ & $\begin{array}{c}2624 \\
(51.2)\end{array}$ & $\begin{array}{c}5121 \\
(100.0)\end{array}$ & \\
\hline
\end{tabular}

* Significant at $\mathrm{P}<0.05 \bullet$ statistički značajno na $\mathrm{P}<0,05$

Table 2 Distribution of maxillary teeth, mandibular teeth, and all maxillary and mandibular teeth together among both genders according to canal configuration

Tablica 2. Distribucija gornjih zuba, donjih zuba i svih gornjih i donjih zuba zajedno među oba spola prema konfiguraciji kanala

\begin{tabular}{|c|c|c|c|c|c|c|c|c|c|c|c|c|c|c|c|c|c|}
\hline & \multirow{3}{*}{\multicolumn{4}{|c|}{$\begin{array}{c}\text { Maxillary teeth } \bullet \text { Gornji zubi } \\
\text { All teeth }^{\dagger} \bullet \text { Svi zubi }\end{array}$}} & \multicolumn{12}{|c|}{ Mandibular teeth $\bullet$ Donji zubi } \\
\hline & & & & & & \multirow{2}{*}{\multicolumn{4}{|c|}{$\begin{array}{l}\text { Anterior teeth and Premolars } \\
\text { Prednji zubi i pretkutnjaci }\end{array}$}} & \multicolumn{8}{|c|}{ Molars ( $1^{\text {st }}$ and $2^{\text {nd }}$ molars) $\bullet$ Kutnjaci (1 i 2 kutnjak) } \\
\hline & & & & & & & & & & \multicolumn{4}{|c|}{ Mesial root $\bullet$ Mezijalni korijen } & \multicolumn{4}{|c|}{ Distal root $\bullet$ Distalni korijen } \\
\hline & & M & $\mathrm{F} \bullet \mathrm{Z}$ & $\begin{array}{l}\text { Total } \\
\text { Ukupno }\end{array}$ & $\mathbf{P}$ & M & $\mathrm{F} \bullet \mathrm{Z}$ & $\begin{array}{l}\text { Total } \\
\text { Ukupno }\end{array}$ & $\mathbf{P}$ & M & $\mathrm{F} \bullet \mathrm{Z}$ & $\begin{array}{l}\text { Total } \\
\text { Ukupno }\end{array}$ & $\mathbf{P}$ & M & $\mathrm{F} \bullet \mathrm{Z}$ & $\begin{array}{l}\text { Total } \\
\text { Ukupno }\end{array}$ & $\mathbf{P}$ \\
\hline \multirow{8}{*}{ 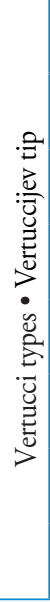 } & $\begin{array}{l}\text { Type I } \\
\text { Tip I }\end{array}$ & $\begin{array}{c}672 \\
(55.7) \\
\end{array}$ & $\begin{array}{c}771 \\
(60.2)\end{array}$ & $\begin{array}{l}1443 \\
(58.0)\end{array}$ & \multirow{9}{*}{ 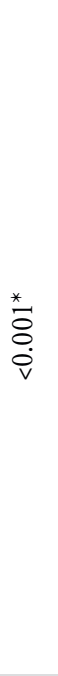 } & $\begin{array}{c}751 \\
(77.7) \\
\end{array}$ & $\begin{array}{c}851 \\
(81.7)\end{array}$ & $\begin{array}{l}1602 \\
(79.8)\end{array}$ & \multirow{9}{*}{$\begin{array}{l}\stackrel{*}{0} \\
\stackrel{0}{0} \\
0\end{array}$} & $\begin{array}{c}10 \\
(3.1)\end{array}$ & $\begin{array}{c}14 \\
(4.6)\end{array}$ & $\begin{array}{c}24 \\
(3.8)\end{array}$ & \multirow{9}{*}{$\begin{array}{l}\text { ¿̂े } \\
\text { ஸे }\end{array}$} & $\begin{array}{c}267 \\
(82.4) \\
\end{array}$ & $\begin{array}{c}255 \\
(84.2)\end{array}$ & $\begin{array}{c}522 \\
(83.3) \\
\end{array}$ & \multirow{9}{*}{$\begin{array}{l}\vec{\Xi} \\
\dot{0} \\
\dot{v}\end{array}$} \\
\hline & $\begin{array}{l}\text { Type II • } \\
\text { Tip II }\end{array}$ & $\begin{array}{c}132 \\
(10.9) \\
\end{array}$ & $\begin{array}{l}122 \\
(9.5)\end{array}$ & $\begin{array}{c}254 \\
(10.2) \\
\end{array}$ & & $\begin{array}{c}0 \\
(0.0) \\
\end{array}$ & $\begin{array}{c}0 \\
(0.0)\end{array}$ & $\begin{array}{c}0 \\
(0.0)\end{array}$ & & $\begin{array}{c}89 \\
(27.5) \\
\end{array}$ & $\begin{array}{c}102 \\
(33.7)\end{array}$ & $\begin{array}{c}191 \\
(30.5)\end{array}$ & & $\begin{array}{c}1 \\
(0.3)\end{array}$ & $\begin{array}{c}11 \\
(3.6)\end{array}$ & $\begin{array}{c}12 \\
(1.9)\end{array}$ & \\
\hline & $\begin{array}{l}\text { Type III } \bullet \\
\text { Tip III }\end{array}$ & $\begin{array}{c}39 \\
(3.2)\end{array}$ & $\begin{array}{c}61 \\
(4.8)\end{array}$ & $\begin{array}{c}100 \\
(4.0)\end{array}$ & & $\begin{array}{c}163 \\
(16.9) \\
\end{array}$ & $\begin{array}{c}124 \\
(11.9)\end{array}$ & $\begin{array}{c}287 \\
(14.3)\end{array}$ & & $\begin{array}{c}29 \\
(9.0)\end{array}$ & $\begin{array}{c}29 \\
(9.6)\end{array}$ & $\begin{array}{c}58 \\
(9.3)\end{array}$ & & $\begin{array}{c}27 \\
(8.3)\end{array}$ & $\begin{array}{c}26 \\
(8.6)\end{array}$ & $\begin{array}{c}53 \\
(8.5)\end{array}$ & \\
\hline & $\begin{array}{l}\text { Type IV • } \\
\text { Tip IV }\end{array}$ & $\begin{array}{c}302 \\
(25.0) \\
\end{array}$ & $\begin{array}{c}245 \\
(19.1) \\
\end{array}$ & $\begin{array}{c}547 \\
(22.0) \\
\end{array}$ & & $\begin{array}{c}0 \\
(0.0) \\
\end{array}$ & $\begin{array}{c}0 \\
(0.0)\end{array}$ & $\begin{array}{c}0 \\
(0.0)\end{array}$ & & $\begin{array}{c}170 \\
(52.5) \\
\end{array}$ & $\begin{array}{c}131 \\
(43.2) \\
\end{array}$ & $\begin{array}{c}301 \\
(48.0)\end{array}$ & & $\begin{array}{c}0 \\
(0.0) \\
\end{array}$ & $\begin{array}{c}2 \\
(0.7) \\
\end{array}$ & $\begin{array}{c}2 \\
(0.3) \\
\end{array}$ & \\
\hline & $\begin{array}{l}\text { Type V• } \\
\text { Tip V }\end{array}$ & $\begin{array}{c}40 \\
(3.3)\end{array}$ & $\begin{array}{c}69 \\
(5.4)\end{array}$ & $\begin{array}{l}109 \\
(4.4)\end{array}$ & & \begin{tabular}{|c|}
49 \\
$(5.1)$ \\
\end{tabular} & $\begin{array}{c}63 \\
(6.1)\end{array}$ & $\begin{array}{c}112 \\
(5.6)\end{array}$ & & $\begin{array}{c}26 \\
(8.0)\end{array}$ & $\begin{array}{c}27 \\
(8.9)\end{array}$ & $\begin{array}{c}53 \\
(8.5)\end{array}$ & & $\begin{array}{c}29 \\
(9.0) \\
\end{array}$ & $\begin{array}{c}9 \\
(3.0)\end{array}$ & $\begin{array}{c}38 \\
(6.1)\end{array}$ & \\
\hline & $\begin{array}{l}\text { Type VI • } \\
\text { Tip VI }\end{array}$ & $\begin{array}{c}9 \\
(0.7)\end{array}$ & $\begin{array}{c}3 \\
(0.2)\end{array}$ & $12(0.5)$ & & $\begin{array}{c}0 \\
(0.0) \\
\end{array}$ & $\begin{array}{c}0 \\
(0.0)\end{array}$ & $\begin{array}{c}0 \\
(0.0)\end{array}$ & & $\begin{array}{c}0 \\
(0.0)\end{array}$ & $\begin{array}{c}0 \\
(0.0)\end{array}$ & $\begin{array}{c}0 \\
(0.0)\end{array}$ & & $\begin{array}{c}0 \\
(0.0)\end{array}$ & $\begin{array}{c}0 \\
(0.0)\end{array}$ & $\begin{array}{c}0 \\
(0.0)\end{array}$ & \\
\hline & $\begin{array}{l}\text { Type VII } \\
\text { • Tip VII }\end{array}$ & $\begin{array}{c}5 \\
(0.4)\end{array}$ & $\begin{array}{c}3 \\
(0.2)\end{array}$ & $\begin{array}{c}8 \\
(0.3)\end{array}$ & & $\begin{array}{c}0 \\
(0.0) \\
\end{array}$ & $\begin{array}{c}1 \\
(0.1)\end{array}$ & $\begin{array}{c}1 \\
(0.0)\end{array}$ & & $\begin{array}{c}0 \\
(0.0)\end{array}$ & $\begin{array}{c}0 \\
(0.0)\end{array}$ & $\begin{array}{c}0 \\
(0.0)\end{array}$ & & $\begin{array}{c}0 \\
(0.0)\end{array}$ & $\begin{array}{c}0 \\
(0.0)\end{array}$ & $\begin{array}{c}0 \\
(0.0)\end{array}$ & \\
\hline & $\begin{array}{l}\text { Others • } \\
\text { Ostalo }\end{array}$ & $\begin{array}{c}7 \\
(0.6) \\
\end{array}$ & $\begin{array}{c}6 \\
(0.5) \\
\end{array}$ & $13(0.5)$ & & $\begin{array}{c}4 \\
(0.4) \\
\end{array}$ & $\begin{array}{c}2 \\
(0.2)\end{array}$ & $\begin{array}{c}6 \\
(0.3) \\
\end{array}$ & & $\begin{array}{c}0 \\
(0.0) \\
\end{array}$ & $\begin{array}{c}0 \\
(0.0)\end{array}$ & $\begin{array}{c}0 \\
(0.0)\end{array}$ & & $\begin{array}{c}0 \\
(0.0) \\
\end{array}$ & $\begin{array}{c}0 \\
(0.0)\end{array}$ & $\begin{array}{c}0 \\
(0.0)\end{array}$ & \\
\hline & $\begin{array}{l}\text { al } \bullet \\
\text { upno }\end{array}$ & $\begin{array}{c}1206 \\
(48.5)\end{array}$ & $\begin{array}{l}1280 \\
(51.5)\end{array}$ & \begin{tabular}{|c|}
2486 \\
$(100.0)$
\end{tabular} & & $\begin{array}{c}967 \\
(48.2)\end{array}$ & $\begin{array}{l}1041 \\
(51.8)\end{array}$ & $\begin{array}{c}2008 \\
(100.0)\end{array}$ & & $\begin{array}{c}324 \\
(51.7)\end{array}$ & $\begin{array}{c}303 \\
(48.3)\end{array}$ & $\begin{array}{c}627 \\
(100.0)\end{array}$ & & $\begin{array}{c}324 \\
(51.7)\end{array}$ & $\begin{array}{c}303 \\
(48.3)\end{array}$ & $\begin{array}{c}627 \\
(100.0)\end{array}$ & \\
\hline
\end{tabular}

* Significant at $P<0.05 \bullet$ statistički značajno na $P<0,05$; ${ }^{\dagger}$ Only mesiobuccal roots of maxillary teeth were included in the analysis $\bullet$ samo meziobukalni korijeni gornjih zuba uključeni su u analizu

\section{Maxillary teeth (Tables 3 and 4)}

\section{Central incisors}

In comparison between males and females, 200 (52.1\%) teeth were found in females and $184(47.9 \%)$ teeth in males. However, the significance of difference could not be computed because all teeth (100\%) in males and all teeth $(100 \%)$ in females had one root, one canal, and Vertucci type I.
Gornji zubi (tablice 3. i 4.)

\section{Središnji sjekutići}

Za usporedbu između muškaraca i žena pronađeno je 200 $(52,1 \%)$ zuba kod žena i $184(47,9 \%)$ kod muškaraca. No nije se mogla ustanoviti statistička značajnost razlike jer su svi zubi (100 \%) kod muškaraca i svi zubi (100 \%) kod žena imali jedan korijen, jedan kanal i tip I prema Vertucciju. 

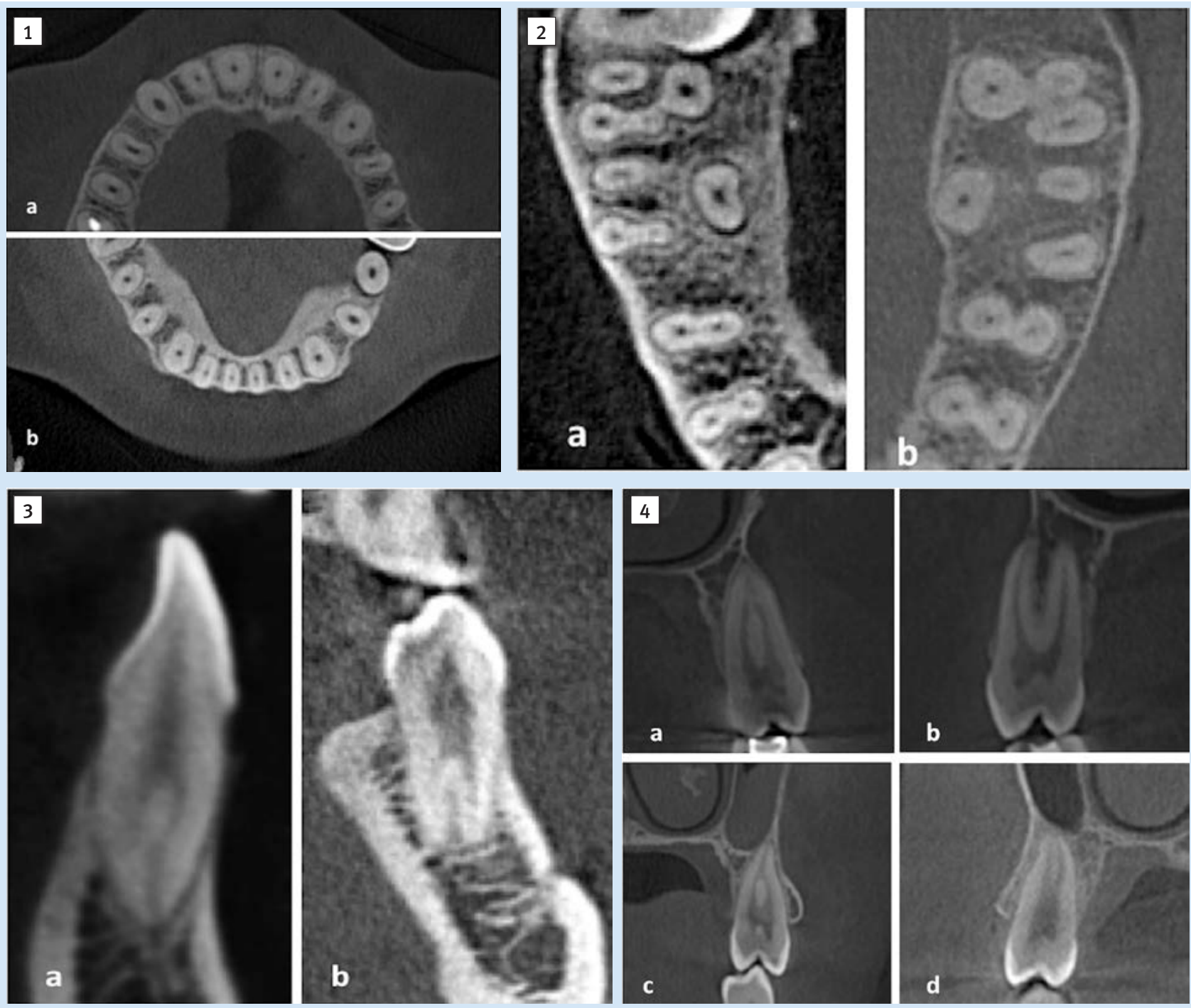

Figure 1 CBCT axial sections showing maxillary (a) and mandibular (b) anterior and premolar teeth with one canal and Vertucci Type I

Slika 1. Aksijalni presjeci CBCT-a prikazuju maksilarni (a) i mandibularni (b) prednji i premolarni zub s jednim kanalom i Vertuccijevim tipom

Figure 2 CBCT axial sections showing maxillary molars with 4 canals and premolars with 2 canals (a); and mandibular molars with 3 canals and premolars with 2 canals (b)

Slika 2. Aksijalni presjeci CBCT koji prikazuju maksilarne kutnjake s 4 kanala i premolare s 2 kanala (a); i mandibularni kutnjaci s 3 kanala i premolari s 2 kanala (b)

Figure 3 CBCT images showing sagittal sections (a) of mandibular central incisors with 2 canals and Vertucci type III; and coronal sections (b) of mandibular first premolar with 2 canals and Vertucci type $V$.

Slika 3. CBCT slike koje prikazuju sagitalne presjeke (a) mandibularnih sjekutića s 2 kanala i Vertuccijevim tipom III; i koronalni presjeci (b) mandibularnog prvog premolara s 2 kanala i Vertuccijeva tipa V.

Figure 4 CBCT coronal sections showing different Vertucci types in maxillary premolars; Type II (a), Type IV (b), Type III (c), Type V (d).

Slika 4. CBCT koronalni presjeci koji prikazuju različite vrste Vertuccija u maksilarnim premolarima; Tip II (a), Tip IV (b), Tip III (c), Tip V (d).

\section{Lateral incisors}

Similar to central incisors, the number of teeth in females was larger than in males $(200(52.1 \%)$ teeth in females compared to $184(47.9 \%)$ teeth in males). Also, the significance of difference was not applicable because all teeth (100\%) in females and all teeth $(100 \%)$ in males had one root, one canal, and belonged to Vertucci type I.

\section{Canines}

There were $200(52 \%)$ teeth in females and 180 (48\%) teeth in males. All teeth (100\%) in both genders had one root. All teeth $(100 \%)$ in females had one canal while, in males, $180(97.8 \%)$ teeth had one canal, and $4(2.2 \%)$ teeth had 2 canals, with no significant differences between both

\section{Bočni sjekutići}

Slično središnjim sjekutićima, broj zuba kod žena bio je veći negoli kod muškaraca (200/52,1 \% zuba kod žena u usporedbi s 184/47,9 \% zuba kod muškaraca). Statistička značajnost razlike također nije bila primjenjiva jer su svi zubi $(100 \%)$ kod žena i svi zubi $(100 \%)$ kod muškaraca imali jedan korijen, jedan kanal i pripadali su Vertuccijevu tipu I.

\section{Očnjaci}

Kod žena je analizirano 200 (52\%) zuba, kod muškaraca 180 (48 \%). Svi zubi (100 \%) u oba su spola imali jedan korijen. Svi zubi (100\%) kod žena imali su jedan kanal, a kod muškaraca $180(97,8 \%)$ zuba imalo je jedan kanal, a četiri $(2,2 \%)$ zuba dva kanala, bez značajnih razlika između spolo- 
Table 3 Distribution of maxillary teeth among both genders according to number of roots, and number of canals Tablica 3. Distribucija gornjih zuba u oba spola prema broju korijena i kanala

\begin{tabular}{|c|c|c|c|c|c|c|c|c|c|c|c|c|c|c|c|}
\hline & & \multicolumn{2}{|c|}{$\begin{array}{l}\text { Central • } \\
\text { Središnji } \\
\text { sjekutić }\end{array}$} & \multicolumn{2}{|c|}{$\begin{array}{l}\text { Lateral • Bočni } \\
\text { sjekutić }\end{array}$} & \multicolumn{2}{|c|}{$\begin{array}{l}\text { Canine • } \\
\text { Očnjak }\end{array}$} & \multicolumn{2}{|c|}{$\begin{array}{l}1^{\text {st }} \text { Premolar } \\
1 . \text { pretkutnjak }\end{array}$} & \multicolumn{2}{|c|}{$\begin{array}{l}2^{\text {nd }} \text { Premolar } \\
\text { 2. pretkutnjak }\end{array}$} & \multicolumn{2}{|c|}{$\begin{array}{l}1^{\text {st }} \text { Molar } \\
1 . \text { kutnjak }\end{array}$} & \multicolumn{2}{|c|}{$\begin{array}{l}2^{\text {nd }} \text { Molar } \bullet \\
\text { 2. kutnjak }\end{array}$} \\
\hline & & M & $\mathrm{F} \bullet \mathrm{Z}$ & M & $\mathrm{F} \bullet \check{Z}$ & M & $\mathrm{F} \bullet \check{\mathrm{Z}}$ & M & $\mathrm{F} \bullet \mathrm{Z}$ & M & $\mathrm{F} \bullet \check{\mathrm{Z}}$ & M & $\mathrm{F} \cdot \check{\mathrm{Z}}$ & M & $\mathrm{F} \cdot \check{\mathrm{Z}}$ \\
\hline \multirow{3}{*}{ 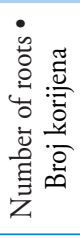 } & $\begin{array}{l}1 \text { root } \bullet \\
1 \text { korijen }\end{array}$ & $\begin{array}{c}184 \\
(47.9) \\
\end{array}$ & $\begin{array}{c}200 \\
(52.1) \\
\end{array}$ & $\begin{array}{c}184 \\
(48.2) \\
\end{array}$ & $\begin{array}{c}200 \\
(51.8) \\
\end{array}$ & $\begin{array}{c}184 \\
(100.0) \\
\end{array}$ & $\begin{array}{c}200 \\
(100.0) \\
\end{array}$ & $\begin{array}{c}63 \\
(36.0) \\
\end{array}$ & $\begin{array}{c}80 \\
(45.5) \\
\end{array}$ & $\begin{array}{c}160 \\
(87.9) \\
\end{array}$ & $\begin{array}{c}156 \\
(88.1) \\
\end{array}$ & $\begin{array}{c}0 \\
(0.0) \\
\end{array}$ & $\begin{array}{c}0 \\
(0.0) \\
\end{array}$ & $\begin{array}{c}0 \\
(0.0) \\
\end{array}$ & $\begin{array}{c}0 \\
(0.0) \\
\end{array}$ \\
\hline & \begin{tabular}{|l|}
2 roots $\bullet$ \\
2 korijena \\
\end{tabular} & $\begin{array}{c}0 \\
(0.0) \\
\end{array}$ & $\begin{array}{c}0 \\
(0.0) \\
\end{array}$ & $\begin{array}{c}0 \\
(0.0) \\
\end{array}$ & $\begin{array}{c}0 \\
(0.0) \\
\end{array}$ & $\begin{array}{c}0 \\
(0.0) \\
\end{array}$ & $\begin{array}{c}0 \\
(0.0) \\
\end{array}$ & $\begin{array}{c}108 \\
(61.7) \\
\end{array}$ & $\begin{array}{c}94 \\
(53.4) \\
\end{array}$ & $\begin{array}{c}22 \\
(12.1) \\
\end{array}$ & $\begin{array}{c}21 \\
(11.9) \\
\end{array}$ & $\begin{array}{c}0 \\
(0.0) \\
\end{array}$ & $\begin{array}{c}0 \\
(0.0) \\
\end{array}$ & $\begin{array}{c}0 \\
(0.0) \\
\end{array}$ & $\begin{array}{c}0 \\
(0.0) \\
\end{array}$ \\
\hline & $\begin{array}{l}3 \text { roots } \bullet \\
3 \text { korijena } \\
\end{array}$ & $\begin{array}{c}0 \\
(0.0) \\
\end{array}$ & $\begin{array}{c}0 \\
(0.0) \\
\end{array}$ & $\begin{array}{c}0 \\
(0.0) \\
\end{array}$ & $\begin{array}{c}0 \\
(0.0) \\
\end{array}$ & $\begin{array}{c}0 \\
(0.0) \\
\end{array}$ & $\begin{array}{c}0 \\
(0.0) \\
\end{array}$ & $4(2.3)$ & $\begin{array}{c}2 \\
(1.1) \\
\end{array}$ & $\begin{array}{c}0 \\
(0.0) \\
\end{array}$ & $\begin{array}{c}0 \\
(0.0) \\
\end{array}$ & $\begin{array}{c}151 \\
(100.0) \\
\end{array}$ & $\begin{array}{c}179 \\
(100.0) \\
\end{array}$ & $\begin{array}{c}144 \\
(100.0) \\
\end{array}$ & $\begin{array}{c}148 \\
(100.0) \\
\end{array}$ \\
\hline \multirow{4}{*}{ 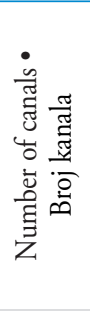 } & $\begin{array}{l}1 \text { canal } \bullet \\
1 \text { kanal } \\
\end{array}$ & $\begin{array}{c}184 \\
(47.9) \\
\end{array}$ & $\begin{array}{c}200 \\
(52.1) \\
\end{array}$ & $\begin{array}{c}184 \\
(48.2) \\
\end{array}$ & $\begin{array}{c}200 \\
(51.8) \\
\end{array}$ & $\begin{array}{c}180 \\
(97.8) \\
\end{array}$ & $\begin{array}{c}200 \\
(100.0)\end{array}$ & $9(5.1)$ & $\begin{array}{c}4 \\
(2.3) \\
\end{array}$ & $\begin{array}{c}62 \\
(34.1) \\
\end{array}$ & $\begin{array}{c}75 \\
(42.4) \\
\end{array}$ & $\begin{array}{c}0 \\
(0.0) \\
\end{array}$ & $\begin{array}{c}0 \\
(0.0) \\
\end{array}$ & $\begin{array}{c}0 \\
(0.0) \\
\end{array}$ & $\begin{array}{c}0 \\
(0.0) \\
\end{array}$ \\
\hline & $\begin{array}{l}2 \text { canals } \\
2 \text { kanala }\end{array}$ & $\begin{array}{c}0 \\
(0.0) \\
\end{array}$ & $\begin{array}{c}0 \\
(0.0) \\
\end{array}$ & $\begin{array}{c}0 \\
(0.0) \\
\end{array}$ & $\begin{array}{c}0 \\
(0.0) \\
\end{array}$ & $\begin{array}{c}4 \\
(2.2) \\
\end{array}$ & $\begin{array}{c}0 \\
(0.0) \\
\end{array}$ & $\begin{array}{c}158 \\
(90.3) \\
\end{array}$ & $\begin{array}{c}169 \\
(96.0)\end{array}$ & $\begin{array}{c}120 \\
(65.9)\end{array}$ & $\begin{array}{c}99 \\
(55.9) \\
\end{array}$ & $\begin{array}{c}0 \\
(0.0)\end{array}$ & $\begin{array}{c}0 \\
(0.0)\end{array}$ & $\begin{array}{c}0 \\
(0.0) \\
\end{array}$ & $\begin{array}{c}0 \\
(0.0) \\
\end{array}$ \\
\hline & $\begin{array}{l}3 \text { canals } \bullet \\
3 \text { kanala } \\
\end{array}$ & $\begin{array}{c}0 \\
(0.0) \\
\end{array}$ & $\begin{array}{c}0 \\
(0.0) \\
\end{array}$ & $\begin{array}{c}0 \\
(0.0) \\
\end{array}$ & $\begin{array}{c}0 \\
(0.0) \\
\end{array}$ & $\begin{array}{c}0 \\
(0.0) \\
\end{array}$ & $\begin{array}{c}0 \\
(0.0) \\
\end{array}$ & $6(3.4)$ & $\begin{array}{c}3 \\
(1.7) \\
\end{array}$ & $\begin{array}{c}0 \\
(0.0) \\
\end{array}$ & $\begin{array}{c}3 \\
(1.7) \\
\end{array}$ & $13(8.6)$ & $\begin{array}{c}34 \\
(19.0) \\
\end{array}$ & $\begin{array}{c}40 \\
(27.8) \\
\end{array}$ & $\begin{array}{c}58 \\
(39.2) \\
\end{array}$ \\
\hline & $\begin{array}{l}4 \text { canals } \\
4 \text { kanala }\end{array}$ & $\begin{array}{c}0 \\
(0.0)\end{array}$ & $\begin{array}{c}0 \\
(0.0)\end{array}$ & $\begin{array}{c}0 \\
(0.0)\end{array}$ & $\begin{array}{c}0 \\
(0.0)\end{array}$ & $\begin{array}{c}0 \\
(0.0)\end{array}$ & $\begin{array}{c}0 \\
(0.0)\end{array}$ & $2(1.1)$ & $\begin{array}{c}0 \\
(0.0)\end{array}$ & $\begin{array}{c}0 \\
(0.0)\end{array}$ & $\begin{array}{c}0 \\
(0.0)\end{array}$ & $\begin{array}{c}138 \\
(91.4)\end{array}$ & $\begin{array}{c}145 \\
(81.0)\end{array}$ & $\begin{array}{c}104 \\
(72.2)\end{array}$ & $\begin{array}{c}90 \\
(60.8)\end{array}$ \\
\hline
\end{tabular}

Bold numbers refer to significant difference $(P<0.05)$; Only mesiobuccal roots of $1^{\text {st }}$ and $2^{\text {nd }}$ molars were included in analysis $\bullet$ Podebljani brojevi odnose se na statistički značajnu razliku $(P<0,05)$; samo meziobukalni korijeni 1. i 2. kutnjaka uključeni su u analizu

\begin{tabular}{|c|c|c|c|c|c|c|c|c|c|c|c|c|c|c|c|}
\hline & & \multicolumn{2}{|c|}{$\begin{array}{l}\text { Central • } \\
\text { Središnji } \\
\text { sjekutić }\end{array}$} & \multicolumn{2}{|c|}{$\begin{array}{c}\text { Lateral • Bočni } \\
\text { sjekutić }\end{array}$} & \multicolumn{2}{|c|}{$\begin{array}{l}\text { Canine• } \\
\text { Očnjak }\end{array}$} & \multicolumn{2}{|c|}{$\begin{array}{l}1^{\text {st }} \text { Premolar } \\
\text { 1. pretkutnjak }\end{array}$} & \multicolumn{2}{|c|}{$\begin{array}{l}2^{\text {nd }} \text { Premolar } \bullet \\
\text { 2. pretkutnjak }\end{array}$} & \multicolumn{2}{|c|}{$\begin{array}{l}1^{\text {st }} \text { Molar • } \\
\text { 1. kutnjak }\end{array}$} & \multicolumn{2}{|c|}{$\begin{array}{l}2^{\text {nd }} \text { Molar } \\
\text { 2. kutnjak }\end{array}$} \\
\hline & & M & $\mathrm{F} \bullet \check{Z}$ & M & $\mathbf{F} \bullet \check{Z}$ & M & $\mathrm{F} \cdot \check{\mathbf{Z}}$ & M & $\mathbf{F} \bullet \check{Z}$ & M & $\mathbf{F} \bullet \check{Z}$ & M & $\mathbf{F} \cdot \check{Z}$ & M & $\mathrm{F} \cdot \check{\mathrm{Z}}$ \\
\hline \multirow{8}{*}{ 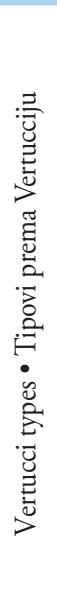 } & $\begin{array}{l}\text { Type I • } \\
\text { Tip I }\end{array}$ & $\begin{array}{c}184 \\
(47.9)\end{array}$ & $\begin{array}{c}200 \\
(52.1)\end{array}$ & $\begin{array}{c}184 \\
(48.2)\end{array}$ & $\begin{array}{c}200 \\
(51.8)\end{array}$ & $\begin{array}{c}180 \\
(97.8)\end{array}$ & $\begin{array}{c}200 \\
(100.0)\end{array}$ & $9(5.1)$ & $\begin{array}{c}4 \\
(2.3)\end{array}$ & $\begin{array}{c}62 \\
(34.1)\end{array}$ & $\begin{array}{c}75 \\
(42.4)\end{array}$ & $13(8.6)$ & $\begin{array}{c}32 \\
(17.9)\end{array}$ & $\begin{array}{c}38 \\
(26.4)\end{array}$ & $\begin{array}{c}58 \\
(39.2)\end{array}$ \\
\hline & \begin{tabular}{|l|} 
Type II • \\
Tip II \\
\end{tabular} & $\begin{array}{c}0 \\
(0.0)\end{array}$ & $\begin{array}{c}0 \\
(0.0)\end{array}$ & $\begin{array}{c}0 \\
(0.0)\end{array}$ & $\begin{array}{c}0 \\
(0.0)\end{array}$ & $\begin{array}{c}0 \\
(0.0)\end{array}$ & $\begin{array}{c}0 \\
(0.0)\end{array}$ & $\begin{array}{c}18 \\
(10.3)\end{array}$ & $\begin{array}{c}6 \\
(3.4)\end{array}$ & $\begin{array}{c}23 \\
(12.6)\end{array}$ & $16(9.0)$ & $\begin{array}{c}54 \\
(35.8)\end{array}$ & $\begin{array}{c}62 \\
(34.6) \\
\end{array}$ & $\begin{array}{c}37 \\
(25.7)\end{array}$ & $\begin{array}{c}40 \\
(27.0)\end{array}$ \\
\hline & \begin{tabular}{|l} 
Type III • \\
Tip III \\
\end{tabular} & $\begin{array}{c}0 \\
(0.0)\end{array}$ & $\begin{array}{c}0 \\
(0.0)\end{array}$ & $\begin{array}{c}0 \\
(0.0)\end{array}$ & $\begin{array}{c}0 \\
(0.0)\end{array}$ & $\begin{array}{c}4 \\
(2.2)\end{array}$ & $\begin{array}{c}0 \\
(0.0)\end{array}$ & $7(4.0)$ & $\begin{array}{c}20 \\
(11.4)\end{array}$ & $\begin{array}{c}24 \\
(13.2)\end{array}$ & $\begin{array}{c}31 \\
(17.5)\end{array}$ & $\begin{array}{c}3 \\
(2.0)\end{array}$ & $\begin{array}{c}3 \\
(1.7)\end{array}$ & $\begin{array}{c}1 \\
(0.7)\end{array}$ & $\begin{array}{c}7 \\
(4.7)\end{array}$ \\
\hline & \begin{tabular}{|l} 
Type IV • \\
Tip IV
\end{tabular} & $\begin{array}{c}0 \\
(0.0)\end{array}$ & $\begin{array}{c}0 \\
(0.0)\end{array}$ & $\begin{array}{c}0 \\
(0.0)\end{array}$ & $\begin{array}{c}0 \\
(0.0)\end{array}$ & $\begin{array}{c}0 \\
(0.0)\end{array}$ & $\begin{array}{c}0 \\
(0.0)\end{array}$ & $\begin{array}{c}119 \\
(68.0)\end{array}$ & $\begin{array}{c}105 \\
(59.7)\end{array}$ & $\begin{array}{c}41 \\
(22.5)\end{array}$ & $\begin{array}{c}28 \\
(15.8)\end{array}$ & $\begin{array}{c}79 \\
(52.3)\end{array}$ & $\begin{array}{c}80 \\
(44.7)\end{array}$ & $\begin{array}{c}63 \\
(43.8)\end{array}$ & $\begin{array}{c}32 \\
(21.6)\end{array}$ \\
\hline & $\begin{array}{l}\text { Type V・ } \\
\text { Tip V } \\
\end{array}$ & $\begin{array}{c}0 \\
(0.0)\end{array}$ & $\begin{array}{c}0 \\
(0.0)\end{array}$ & $\begin{array}{c}0 \\
(0.0)\end{array}$ & $\begin{array}{c}0 \\
(0.0)\end{array}$ & $\begin{array}{c}0 \\
(0.0)\end{array}$ & $\begin{array}{c}0 \\
(0.0)\end{array}$ & $15(8.6)$ & $\begin{array}{c}37 \\
(21.0)\end{array}$ & $\begin{array}{c}23 \\
(12.6) \\
\end{array}$ & $\begin{array}{c}21 \\
(11.9)\end{array}$ & $\begin{array}{c}0 \\
(0.0)\end{array}$ & $\begin{array}{c}2 \\
(1.1)\end{array}$ & $\begin{array}{c}2 \\
(1.4)\end{array}$ & $\begin{array}{c}9 \\
(6.1)\end{array}$ \\
\hline & $\begin{array}{l}\text { Type VI • } \\
\text { Tip VI }\end{array}$ & $\begin{array}{c}0 \\
(0.0)\end{array}$ & $\begin{array}{c}0 \\
(0.0) \\
\end{array}$ & $\begin{array}{c}0 \\
(0.0)\end{array}$ & $\begin{array}{c}0 \\
(0.0)\end{array}$ & $\begin{array}{c}0 \\
(0.0)\end{array}$ & $\begin{array}{c}0 \\
(0.0)\end{array}$ & $0(0.0)$ & $\begin{array}{c}1 \\
(0.6)\end{array}$ & $\begin{array}{c}4 \\
(2.2)\end{array}$ & $\begin{array}{c}0 \\
(0.0) \\
\end{array}$ & $\begin{array}{c}2 \\
(1.3)\end{array}$ & $\begin{array}{c}0 \\
(0.0) \\
\end{array}$ & $\begin{array}{c}3 \\
(2.1) \\
\end{array}$ & $\begin{array}{c}2 \\
(1.4)\end{array}$ \\
\hline & \begin{tabular}{|l|} 
Type VII \\
- Tip VII
\end{tabular} & $\begin{array}{c}0 \\
(0.0)\end{array}$ & $\begin{array}{c}0 \\
(0.0)\end{array}$ & $\begin{array}{c}0 \\
(0.0)\end{array}$ & $\begin{array}{c}0 \\
(0.0)\end{array}$ & $\begin{array}{c}0 \\
(0.0)\end{array}$ & $\begin{array}{c}0 \\
(0.0)\end{array}$ & $\begin{array}{c}0 \\
(0.0)\end{array}$ & $\begin{array}{c}0 \\
(0.0)\end{array}$ & $\begin{array}{c}5 \\
(2.7)\end{array}$ & $\begin{array}{c}3 \\
(1.7)\end{array}$ & $\begin{array}{c}0 \\
(0.0)\end{array}$ & $\begin{array}{c}0 \\
(0.0)\end{array}$ & $\begin{array}{c}0 \\
(0.0)\end{array}$ & $\begin{array}{c}0 \\
(0.0)\end{array}$ \\
\hline & $\begin{array}{l}\text { Others • } \\
\text { Ostalo }\end{array}$ & $\begin{array}{c}0 \\
(0.0)\end{array}$ & $\begin{array}{c}0 \\
(0.0)\end{array}$ & $\begin{array}{c}0 \\
(0.0)\end{array}$ & $\begin{array}{c}0 \\
(0.0)\end{array}$ & $\begin{array}{c}0 \\
(0.0)\end{array}$ & $\begin{array}{c}0 \\
(0.0)\end{array}$ & $7(4.0)$ & $\begin{array}{c}3 \\
(1.7)\end{array}$ & $\begin{array}{c}0 \\
(0.0)\end{array}$ & $\begin{array}{c}3 \\
(1.7)\end{array}$ & $\begin{array}{c}0 \\
(0.0)\end{array}$ & $\begin{array}{c}0 \\
(0.0)\end{array}$ & $\begin{array}{c}0 \\
(0.0)\end{array}$ & $\begin{array}{c}0 \\
(0.0)\end{array}$ \\
\hline
\end{tabular}

Bold numbers refer to significant difference $(P<0.05)$; Only mesiobuccal roots of $1^{\text {st }}$ and $2^{\text {nd }}$ molars were included in analysis $\bullet$ Podebljani brojevi odnose se na statistički značajnu razliku $(\mathrm{P}<0,05)$; samo meziobukalni korijeni 1 . i 2 . kutnjaka uključeni su u analizu $\bullet$

genders $(P=0.052)$. Similarly, all teeth $(100 \%)$ in females belonged to Vertucci type I while, $180(97.8 \%)$ teeth in males belonged to Vertucci type I, and $4(2.2 \%)$ teeth belonged to Vertucci type III. No significant differences between both genders were found $(P=0.052)$.

\section{First premolars}

Out of 176 (50.1\% of all maxillary first premolars) teeth in females, $53.4 \%$ had 2 roots, $45.5 \%$ had one root, and $1.1 \%$ (2 teeth) had 3 roots. However, 108 (61.7\%) out of 175 teeth in males had 2 roots, $36 \%$ had one root, and $2.3 \%$ had 3 roots. The difference between both genders was not statistically significant $(P=0.161)$. The majority of teeth in va $(\mathrm{P}=0,052)$. Slično tomu, svi zubi $(100 \%)$ kod žena pripadali su Vertuccijevu tipu I, zatim $180(97,8 \%)$ zuba kod muškaraca pripadalo je Vertuccijevu tipu I, a četiri $(2,2 \%)$ su pripadala tipu III. Nisu ustanovljene značajne razlike između spolova $(\mathrm{P}=0,052)$.

\section{Prvi pretkutnjaci}

Od 176 (50,1\% svih gornjih prvih pretkutnjaka) zuba kod žena, 53,4\% imalo je dva korijena, 45,5\% jedan, a 1,1 $\%$ (2 zuba) tri korijena. S druge strane, $108(61,7 \%)$ od 175 zuba kod muškaraca imalo je dva korijena, $36 \%$ jedan, a $2,3 \%$ tri korijena. Razlika između spolova nije bila statistički značajna $(\mathrm{P}=0,161)$. Većina zuba u oba spola $(96,0 \%$ zuba 
both genders $(96.0 \%$ of teeth in females and $90.3 \%$ of teeth in males) had 2 canals. No teeth in females had 4 canals, and only 2 teeth in males had 4 canals. The teeth with one canal and 3 canals were found in fewer percentages. Similarly, no significant differences were found regarding the number of canals $(P=0.125)$. A significant difference was found between both genders in relation to Vertucci types $(P<0.001)$. More than half of teeth $(59.7 \%)$ in females had Vertucci type IV, followed by Vertucci type V (21.0\%), and Vertucci type III (11.4\%). In males, $68.0 \%$ of teeth had Vertucci type IV, followed by Vertucci type II (10.3\%), and Vertucci type V (8.6\%).

\section{Second premolars}

The distribution of teeth was approximately similar in both genders $(50.7 \%$ in males compared to $49.3 \%$ in females). The majority of teeth in both genders had one root with no significant differences $(P=1.000)$. About two thirds $(65.9 \%)$ of teeth in males and about half of teeth $(55.9 \%)$ in females had 2 canals with a statistically significant difference $(P=0.046)$. The Vertucci type I was found in $62(34.1 \%)$ teeth in males followed by Vertucci type IV which was found in $41(22.5 \%)$ teeth. However, Vertucci type III was found in $31(17.5 \%)$ teeth in females followed by Vertucci type IV which was found in $28(15.8 \%)$ teeth. Nevertheless, no significant differences were found between males and females $(P=0.064)$.

\section{First molars}

In total, 354 molars were evaluated (330 with 3 normal roots and 24 molars were fused-rooted)

\section{Molars with 3 normal roots ( $n=330$ teeth):}

In comparison between both genders, all teeth in males ( $n=151$, representing $45.76 \%$ of 330 molars) and all teeth in females ( $n=179$, representing $54.24 \%$ of 330 molars) had 3 roots with Vertucci type I in distobuccal (DB) and palatal (P) roots. The significance test was not applicable regarding the number of roots. However, a significant difference between males and females was found with regards to the number of canals $(P=0.007)$. Teeth with 4 canals were found in higher percentages in males than in females $(91.4 \%$ in males compared to $81.0 \%$ in females) while, $19.0 \%$ of teeth in females and $8.6 \%$ of teeth in males had 3 canals. Regarding Vertucci types in mesiobuccal roots, the majority of teeth in males and females $(52.3 \%$ and $44.7 \%$, respectively) had Vertucci type IV followed Vertucci type II $35.8 \%$ of teeth in males and $34.6 \%$ of teeth in females). No significant differences between both genders were found $(P=0.068)$.

Fused-rooted molars (24 teeth):

The prevalence of fused-rooted first molars is $7 \%$ out of the total sample (354 molars) with $0.6 \%$ presence of merged canals (only in 2 teeth). The distribution of teeth with nonmerged canals from the fused-rooted molars $(n=22)$ among both genders is presented in Table 5. No significant differences between both genders were found in relation to the number of roots, the number of canals, and Vertucci types.

\section{Second molars}

In total, 370 molars were evaluated (292 with normal 3 roots and 78 were fused-rooted) kod žena i 90,3 \% zuba kod muškaraca) imala je dva kanala. Nijedan zub kod žena nije imao četiri kanala, a samo dva zuba kod muškaraca imala su četiri kanala. Nađeni su zubi s jednim kanalom i trima kanalima u manjem postotku. Slično tomu, nisu ustanovljene značajne razlike u broju kanala (P $=0,125)$. Ustanovljena je značajna razlika između spolova u odnosu prema Vertuccijevim tipovima $(\mathrm{P}<0,001)$. Više od polovine zuba $(59,7 \%)$ kod žena pripadalo je Vertuccijevu tipu IV, zatim tipu V (21,0 \%) i tipu III (11,4 \%). Kod muškaraca $68,0 \%$ zuba pripadalo je tipu IV, zatim tipu II (10,3 \%) i tipu $\mathrm{V}(8,6 \%)$.

\section{Drugi pretkutnjaci}

Raspodjela zuba bila je približno slična u oba spola $(50,7$ $\%$ kod muškaraca u usporedbi s 49,3 \% kod žena). Većina zuba obaju spolova imala je jedan korijen bez značajnih razlika $(\mathrm{P}=1,000)$. Oko dvije trećine $(65,9 \%)$ zuba kod muškaraca i oko polovine zuba $(55,9 \%)$ kod žena imalo je dva kanala sa statistički značajnom razlikom $(P=0,046)$. Vertuccijev tip I pronađen je u $62(34,1 \%)$ zuba kod muškaraca, nakon čega slijedi tip IV koji je pronađen u $41(22,5 \%)$ zubu. No Vertuccijev tip III pronađen je u $31(17,5 \%)$ zubu kod žena, a slijedi tip IV koji je pronađen u $28(15,8 \%)$ zuba. Ipak, nisu ustanovljene značajne razlike između muškaraca i žena $(\mathrm{P}=0,064)$.

\section{Prvi kutnjaci}

Ukupno su procijenjena 354 kutnjaka (330 s trima normalnim korijenima i $24 \mathrm{~s}$ fuzioniranim korijenima).

Kutnjaci s trima normalnim korijenima $(n=330 \mathrm{zuba})$

U usporedbi spolova, svi zubi muškaraca $(\mathrm{n}=151$, što je $45,76 \%$ od 330 kutnjaka) i svi zubi žena ( $n=179$, što je $54,24 \%$ od 330 kutnjaka) imali su tri korijena s Vertuccijevim tipom I u distobukalnom (DB) i palatalnom (P) korijenu. Test statističke značajnosti nije bio primjenjiv s obzirom na broj korijena. No ustanovljena je značajna razlika između muškaraca i žena kad je riječ o broju kanala $(\mathrm{P}=0,007)$. Nađeni su zubi s četirima kanalima u većem postotku kod muškaraca negoli kod žena $(91,4 \%$ kod muškaraca u usporedbi s $81,0 \%$ kod žena), a 19,0\% zuba kod žena i 8,6\% zuba kod muškaraca imalo je tri kanala. Što se tiče Vertuccijevih tipova u meziobukalnim korijenima, većina zuba kod muškaraca i žena $(52,3 \%$ i $44,7 \%)$ pripadala je tipu IV, a slijedio je tip II (35,8 \% zuba kod muškaraca i 34,6\% zuba kod žena). Nisu ustanovljene značajne razlike između spolova $(P=0,068)$.

\section{Kutnjaci s fuzioniranim korijenima (24 zuba)}

Prevalencija prvih kutnjaka $s$ fuzioniranim korijenima iznosila je $7 \%$ od ukupnog uzorka (354 molara) uz 0,6-posototnu prisutnost spojenih kanala (samo u dvama zubima). Rasprostranjenost zuba s nespojenim kanalima kod spojenih korijena $(n=22)$ u oba spola prikazana je u tablici 5 . Nije ustanovljena značajna razlika između spolova u odnosu prema broju korijena, broju kanala i Vertuccijevim tipovima.

\section{Drugi kutnjaci}

Ukupno je procijenjeno 370 kutnjaka (292 s trima normalnim korijenima i 78 s fuzioniranim korijenima) 
Table 5 Distribution of 1st and 2nd maxillary molars with fused roots among both genders according to number of roots, number of canals, and canal configuration

Tablica 5. Distribucija 1. i 2. gornjih kutnjaka s fuzioniranim korijenima u oba spola prema broju korijena, broju i konfiguraciji kanala

\begin{tabular}{|c|c|c|c|c|c|c|c|c|}
\hline & \multicolumn{4}{|c|}{$\begin{array}{l}\text { 1st molar } \bullet 1 . \text { kutnjak } \\
\qquad(\mathrm{N}=22)\end{array}$} & \multicolumn{4}{|c|}{$\begin{array}{l}\text { 2nd molar } \bullet 2 . \text { kutnjak } \\
\qquad(\mathrm{N}=53)\end{array}$} \\
\hline & M & $\mathrm{F} \cdot \check{\mathrm{Z}}$ & $\begin{array}{l}\text { Total } \bullet \\
\text { Ukupno }\end{array}$ & $\mathbf{P}$ & $\mathbf{M}$ & $\mathrm{F} \cdot \check{\mathrm{Z}}$ & $\begin{array}{l}\text { Total } \bullet \\
\text { Ukupno }\end{array}$ & $\mathbf{P}$ \\
\hline \multicolumn{9}{|c|}{ Number of roots $\bullet$ Broj korijena } \\
\hline 1 root $\cdot 1$ korijen & $5(33.3)$ & $1(14.3)$ & $6(27.3)$ & \multirow{3}{*}{0.616} & $1(4.5)$ & $6(19.4)$ & $7(13.2)$ & \multirow{3}{*}{0.218} \\
\hline 2 roots $\bullet 2$ korijena & $10(66.7)$ & $6(85.7)$ & $16(72.7)$ & & $21(95.5)$ & $25(80.6)$ & $46(86.8)$ & \\
\hline Total • Ukupno & $15(68.2)$ & $7(31.8)$ & $22(100.0)$ & & $22(41.5)$ & $31(58.5)$ & $53(100.0)$ & \\
\hline \multicolumn{9}{|c|}{ Number of canals $\bullet$ Broj kanala } \\
\hline 3 canals $\bullet 3$ kanala & $5(33.3)$ & $2(28.6)$ & $7(31.8)$ & \multirow{3}{*}{1.000} & $18(81.8)$ & $20(64.5)$ & $38(71.7)$ & \multirow{3}{*}{0.223} \\
\hline 4 canals $\bullet 4$ kanala & $10(66.7)$ & $5(71.4)$ & $15(68.2)$ & & $4(18.2)$ & $11(35.5)$ & $15(28.3)$ & \\
\hline Total • Ukupno & $15(68.2)$ & $7(31.8)$ & $22(100.0)$ & & $22(41.5)$ & $31(58.5)$ & $53(100.0)$ & \\
\hline \multicolumn{9}{|c|}{ MB. Vertucci types $\bullet$ MB. Vertuccijev tip } \\
\hline Type I • Tip I & $5(33.3)$ & $2(28.6)$ & $7(31.8)$ & \multirow{5}{*}{0.273} & $18(81.8)$ & $20(64.5)$ & $38(71.7)$ & \multirow{5}{*}{0.452} \\
\hline Type II • Tip II & $5(33.3)$ & $5(71.4)$ & $10(45.5)$ & & $2(9.1)$ & $3(9.7)$ & $5(9.4)$ & \\
\hline Type IV • Tip IV & $4(26.7)$ & $0(0.0)$ & $4(18.2)$ & & $2(9.1)$ & $7(22.6)$ & $9(17.0)$ & \\
\hline Type V・Tip V & $1(6.7)$ & $0(0.0)$ & $1(4.5)$ & & $0(0.0)$ & $1(3.2)$ & $1(1.9)$ & \\
\hline Total • Ukupno & $15(68.2)$ & $7(31.8)$ & $22(100.0)$ & & $22(41.5)$ & $31(58.5)$ & $53(100.0)$ & \\
\hline
\end{tabular}

Only mesiobuccal roots were included in the analysis, other roots had Vertucci type I $\bullet$ U analizu su uključeni samo meziobukalni kanali, ostali korijeni imali su Vertuccijev tip I

\section{Molars with normal 3 roots: (292 molars)}

All teeth in males $(n=144$, representing $49.3 \%$ of 292 molars) and all teeth in females ( $\mathrm{n}=148$, representing $50.7 \%$ of 292) had three roots, with Vertucci type I in DB and P roots. A significant difference was found between both genders in relation to number of canals $(P=0.047)$. More than two thirds $(72.2 \%)$ of teeth in males had 4 canals and $27.8 \%$ had 3 canals while, $60.8 \%$ of teeth in females had 4 canals and $39.2 \%$ had 3 canals. The most frequent Vertucci type in mesiobuccal roots in males was Vertucci type IV (43.8\% of teeth), followed by Vertucci type I (26.4\% of teeth), and Vertucci type II ( $25.7 \%$ of teeth). However, this is was not the case in females where the most frequent Vertucci type in mesiobuccal roots was Vertucci type I (39.2\% of teeth), followed by Vertucci type II (27.0\% of teeth), and Vertucci type IV (21.6\% of teeth). Highly significant difference between males and females was found $(P<0.001)$.

\section{Fused-rooted molars: (78 molars)}

There were 78 fused-rooted maxillary second molars representing $21.1 \%$ of all maxillary second molars. Out of them, $32.1 \%$ (25 teeth) had merged canals and 53 (67.9\%) teeth with fused roots but non-merged canals. The distribution of these teeth among both genders is presented in Table 5. No significant differences between males and females were found in relation to number of roots, number of canals, and Vertucci types.

\section{Mandibular teeth (Tables 6-8)}

\section{Central incisors}

Regarding the comparison between males and females, both genders had all their mandibular central incisors with one root. Significance tests could not be computed. Females had more teeth with one canal (170 teeth, representing $79.4 \%$ of teeth in females) compared to males who had
Kutnjaci s trima normalnim korijenima (292 kutnjaka)

Svi zubi kod muškaraca ( $\mathrm{n}=144$, što je $49,3 \%$ od 292 kutnjaka) i svi zubi kod žena ( $\mathrm{n}=148$, što je $50,7 \%$ od 292 kutnjaka) imali su tri korijena, $s$ Vertuccijevim tipom I u korijenu DB-a i P-a. Ustanovljena je značajna razlika između spolova u odnosu prema broju kanala $(\mathrm{P}=0,047)$. Više od dvije trećine $(72,2 \%)$ zuba muškaraca imalo je četiri kanala, a 27,8 \% tri kanala; 60,8\% zuba kod žena imalo je četiri kanala, a 39,2 \% tri. Najčešći Vertuccijev tip u meziobukalnim korijenima kod muškaraca bio je tip IV ( $43,8 \%$ zuba), zatim slijedi tip I (26,4 \% zuba) i tip II (25,7\% zuba). No to nije vrijedilo za žene kod kojih je najčešći Vertuccijev tip u meziobukalnom korijenu bio tip I (39,2\% zuba), zatim slijedi tip II (27,0 \% zuba) i tip IV (21,6\% zuba). Ustanovljena je vrlo značajna razlika između muškaraca i žena $(\mathrm{P}<0,001)$.

\section{Kutnjaci fuzioniranim korijenima (78 kutnjaka)}

Pronađeno je 78 drugih gornjih kutnjaka s fuzioniranim korijenima, što je $21,1 \%$ svih drugih gornjih kutnjaka. Od njih je 32,1 \% (25 zuba) imalo spojene kanale, a $53(67,9 \%)$ zuba spojene korijene, ali odvojene kanale. Raspodjela tih zuba u oba spola nalazi se u tablici 5 . Nisu ustanovljene značajne razlike između muškaraca i žena u odnosu prema broju korijena, broju kanala i Vertuccijevu tipu.

\section{Donji zubi (tablice od 6. do 8.)}

\section{Središnji sjekutići}

Kad je riječ o usporedbi muškaraca i žena, u oba spola svi su središnji sjekutići imali jedan korijen. Testovi značajnosti nisu se mogli primijeniti. Žene su imale više zuba s jednim kanalom (170 zuba, što je 79,4 \%) u usporedbi s muškarcima - oni su imali 132 takva zuba (67,3\%). Prevalencija 
Table 6 Distribution of mandibular teeth (anterior and premolars) among both genders according to number of roots, and number of canals Tablica 6. Distribucija donjih zuba (prednjih i pretkutnjaka) u oba spola prema broju korijena i kanala

\begin{tabular}{|c|c|c|c|c|c|c|c|c|c|c|c|}
\hline & & $\begin{array}{r}\text { Central } \\
\text { sjek }\end{array}$ & $\begin{array}{l}\text { Središnji } \\
\text { utić }\end{array}$ & $\begin{array}{r}\text { Lateral } \\
\text { sjek }\end{array}$ & $\begin{array}{l}\text { - Bočni } \\
\text { utić }\end{array}$ & Canine ${ }^{\circ}$ & Očnjak & $\begin{array}{l}1^{\text {st }} \text { Pren } \\
1 . \text { pretk }\end{array}$ & $\begin{array}{l}\text { nolar } \\
\text { utnjak }\end{array}$ & $\begin{array}{l}2^{\text {nd }} \text { Pre } \\
\text { 2. pretl }\end{array}$ & $\begin{array}{l}\text { nolar } \\
\text { utnjak }\end{array}$ \\
\hline & & M & $\mathrm{F} \cdot \check{\mathrm{Z}}$ & M & $\mathbf{F} \cdot \check{Z}$ & M & $\mathrm{F} \bullet \check{\mathrm{Z}}$ & M & $\mathrm{F} \cdot \check{Z}$ & M & $\mathrm{F} \bullet \check{Z}$ \\
\hline : & $\begin{array}{l}1 \text { root } \bullet \\
1 \text { korijen }\end{array}$ & $196(100)$ & $214(100)$ & $197(99.5)$ & $213(99.5)$ & $195(99.0)$ & 204 (95.8) & $186(98.9)$ & $\begin{array}{c}209 \\
(100.0)\end{array}$ & $\begin{array}{c}188 \\
(100.0)\end{array}$ & $\begin{array}{c}191 \\
(100.0)\end{array}$ \\
\hline 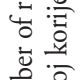 & $\begin{array}{l}2 \text { roots } \bullet \\
2 \text { korijena } \\
\end{array}$ & $\begin{array}{c}0 \\
(0.0) \\
\end{array}$ & $\begin{array}{c}0 \\
(0.0)\end{array}$ & $\begin{array}{c}1 \\
(0.5)\end{array}$ & $\begin{array}{c}1 \\
(0.5)\end{array}$ & $\begin{array}{c}2 \\
(1.0) \\
\end{array}$ & $\begin{array}{c}9 \\
(4.2) \\
\end{array}$ & $\begin{array}{c}2 \\
(1.1) \\
\end{array}$ & $\begin{array}{c}0 \\
(0.0) \\
\end{array}$ & $\begin{array}{c}0 \\
(0.0)\end{array}$ & $\begin{array}{c}0 \\
(0.0) \\
\end{array}$ \\
\hline 言 & $\begin{array}{l}3 \text { roots } \bullet \\
3 \text { korijena }\end{array}$ & $\begin{array}{c}0 \\
(0.0)\end{array}$ & $\begin{array}{c}0 \\
(0.0)\end{array}$ & $\begin{array}{c}0 \\
(0.0)\end{array}$ & $\begin{array}{c}0 \\
(0.0)\end{array}$ & $\begin{array}{c}0 \\
(0.0)\end{array}$ & $\begin{array}{c}0 \\
(0.0)\end{array}$ & $\begin{array}{c}0 \\
(0.0)\end{array}$ & $\begin{array}{c}0 \\
(0.0)\end{array}$ & $\begin{array}{c}0 \\
(0.0)\end{array}$ & $\begin{array}{c}0 \\
(0.0)\end{array}$ \\
\hline & $\begin{array}{l}1 \text { canal } \bullet \\
1 \text { kanal }\end{array}$ & $132(67.3)$ & $\begin{array}{c}170 \\
(79.4)\end{array}$ & $133(67.2)$ & $152(71.0)$ & $184(93.4)$ & $188(88.3)$ & $124(66.0)$ & $152(72.7)$ & 178 (94.7) & $189(99.0)$ \\
\hline 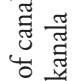 & $\begin{array}{l}2 \text { canals } \\
2 \text { kanala }\end{array}$ & $64(32.7)$ & $44(20.6)$ & $65(32.8)$ & $62(29.0)$ & $\begin{array}{c}13 \\
(6.6)\end{array}$ & $25(11.7)$ & $61(32.4)$ & $56(26.8)$ & $\begin{array}{c}7 \\
(3.7)\end{array}$ & $\begin{array}{c}1 \\
(0.5)\end{array}$ \\
\hline 离 & $\begin{array}{l}3 \text { canals } \\
3 \text { kanala }\end{array}$ & $\begin{array}{c}0 \\
(0.0)\end{array}$ & $\begin{array}{c}0 \\
(0.0)\end{array}$ & $\begin{array}{c}0 \\
(0.0)\end{array}$ & $\begin{array}{c}0 \\
(0.0)\end{array}$ & $\begin{array}{c}0 \\
(0.0)\end{array}$ & $\begin{array}{c}0 \\
(0.0)\end{array}$ & $\begin{array}{c}3 \\
(1.6)\end{array}$ & $\begin{array}{c}1 \\
(0.5)\end{array}$ & $\begin{array}{c}3 \\
(1.6)\end{array}$ & $\begin{array}{c}1 \\
(0.5)\end{array}$ \\
\hline Z & $\begin{array}{l}4 \text { canals } \\
4 \text { kanala }\end{array}$ & $\begin{array}{c}0 \\
(0.0)\end{array}$ & $\begin{array}{c}0 \\
(0.0)\end{array}$ & $\begin{array}{c}0 \\
(0.0)\end{array}$ & $\begin{array}{c}0 \\
(0.0)\end{array}$ & $\begin{array}{c}0 \\
(0.0)\end{array}$ & $\begin{array}{c}0 \\
(0.0)\end{array}$ & $\begin{array}{c}0 \\
(0.0)\end{array}$ & $\begin{array}{c}0 \\
(0.0)\end{array}$ & $\begin{array}{c}0 \\
(0.0)\end{array}$ & $\begin{array}{c}0 \\
(0.0)\end{array}$ \\
\hline
\end{tabular}

Bold numbers refer to significant difference $(P<0.05) \bullet$ Podebljani brojevi odnose se na statistički značajnu razliku $(\mathrm{P}<0,05)$

\begin{tabular}{|c|c|c|c|c|c|c|c|c|c|c|c|}
\hline & & \multicolumn{2}{|c|}{$\begin{array}{c}\text { Central • Središnji } \\
\text { sjekutić }\end{array}$} & \multicolumn{2}{|c|}{$\begin{array}{l}\text { Lateral • Bočni } \\
\text { sjekutić }\end{array}$} & \multicolumn{2}{|c|}{ Canine • Očnjak } & \multicolumn{2}{|c|}{$\begin{array}{l}1^{\text {st }} \text { Premolar • } \\
\text { 1. pretkutnjak }\end{array}$} & \multicolumn{2}{|c|}{$\begin{array}{l}2^{\text {nd }} \text { Premolar } \\
2 . \text { pretkutnjak }\end{array}$} \\
\hline & & M & $\mathrm{F} \cdot \check{\mathrm{Z}}$ & M & $\mathrm{F} \cdot \check{\mathrm{Z}}$ & M & $\mathrm{F} \bullet \check{\mathrm{Z}}$ & M & $\mathrm{F} \cdot \check{Z}$ & M & $\mathrm{F} \cdot \check{Z}$ \\
\hline \multirow{8}{*}{ 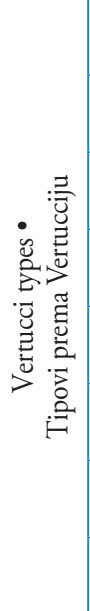 } & Type I • Tip I & $\begin{array}{c}132 \\
(67.3) \\
\end{array}$ & $\begin{array}{c}170 \\
(79.4)\end{array}$ & $\begin{array}{c}133 \\
(67.2) \\
\end{array}$ & $\begin{array}{c}152 \\
(71.0) \\
\end{array}$ & $\begin{array}{c}184 \\
(93.4) \\
\end{array}$ & $\begin{array}{c}188 \\
(88.3)\end{array}$ & $\begin{array}{c}124 \\
(66.0) \\
\end{array}$ & $\begin{array}{c}152 \\
(72,7)\end{array}$ & $\begin{array}{c}178 \\
(94.7)\end{array}$ & $\begin{array}{c}189 \\
(99.0)\end{array}$ \\
\hline & Type II • Tip II & $\begin{array}{c}0 \\
(0.0) \\
\end{array}$ & $\begin{array}{c}0 \\
(0.0) \\
\end{array}$ & $\begin{array}{c}0 \\
(0.0)\end{array}$ & $\begin{array}{c}0 \\
(0.0)\end{array}$ & $\begin{array}{c}0 \\
(0.0)\end{array}$ & $\begin{array}{c}0 \\
(0.0) \\
\end{array}$ & $\begin{array}{c}0 \\
(0.0)\end{array}$ & $\begin{array}{c}0 \\
(0.0)\end{array}$ & $\begin{array}{c}0 \\
(0.0)\end{array}$ & $\begin{array}{c}0 \\
(0.0)\end{array}$ \\
\hline & Type III • Tip III & $64(32.7)$ & $44(20.6)$ & $63(31.8)$ & $60(28.0)$ & $\begin{array}{c}11 \\
(5.6)\end{array}$ & $\begin{array}{c}14 \\
(6.6)\end{array}$ & $20(10.6)$ & $\begin{array}{c}5 \\
(2.4) \\
\end{array}$ & $\begin{array}{c}5 \\
(2.7) \\
\end{array}$ & $\begin{array}{c}1 \\
(0.5)\end{array}$ \\
\hline & Type IV • Tip IV & $\begin{array}{c}0 \\
(0.0) \\
\end{array}$ & $\begin{array}{c}0 \\
(0.0) \\
\end{array}$ & $\begin{array}{c}0 \\
(0.0)\end{array}$ & $\begin{array}{c}0 \\
(0.0) \\
\end{array}$ & $\begin{array}{c}0 \\
(0.0) \\
\end{array}$ & $\begin{array}{c}0 \\
(0.0) \\
\end{array}$ & $\begin{array}{c}0 \\
(0.0) \\
\end{array}$ & $\begin{array}{c}0 \\
(0.0) \\
\end{array}$ & $\begin{array}{c}0 \\
(0.0) \\
\end{array}$ & $\begin{array}{c}0 \\
(0.0) \\
\end{array}$ \\
\hline & Type V・Tip V & $\begin{array}{c}0 \\
(0.0) \\
\end{array}$ & $\begin{array}{c}0 \\
(0.0) \\
\end{array}$ & $\begin{array}{c}2 \\
(1.0) \\
\end{array}$ & $\begin{array}{c}2 \\
(1.0) \\
\end{array}$ & $\begin{array}{c}2 \\
(1.0)\end{array}$ & $\begin{array}{c}11 \\
(5.2) \\
\end{array}$ & $42(22.3)$ & $50(23.9)$ & $\begin{array}{c}3 \\
(1.6)\end{array}$ & $\begin{array}{c}0 \\
(0.0) \\
\end{array}$ \\
\hline & Type VI・Tip VI & $\begin{array}{c}0 \\
(0.0) \\
\end{array}$ & $\begin{array}{c}0 \\
(0.0) \\
\end{array}$ & $\begin{array}{c}0 \\
(0.0) \\
\end{array}$ & $\begin{array}{c}0 \\
(0.0) \\
\end{array}$ & $\begin{array}{c}0 \\
(0.0) \\
\end{array}$ & $\begin{array}{c}0 \\
(0.0) \\
\end{array}$ & $\begin{array}{c}0 \\
(0.0) \\
\end{array}$ & $\begin{array}{c}0 \\
(0.0) \\
\end{array}$ & $\begin{array}{c}0 \\
(0.0)\end{array}$ & $\begin{array}{c}0 \\
(0.0) \\
\end{array}$ \\
\hline & Type VII • Tip VII & $\begin{array}{c}0 \\
(0.0)\end{array}$ & $\begin{array}{c}0 \\
(0.0)\end{array}$ & $\begin{array}{c}0 \\
(0.0)\end{array}$ & $\begin{array}{c}0 \\
(0.0)\end{array}$ & $\begin{array}{c}0 \\
(0.0)\end{array}$ & $\begin{array}{c}0 \\
(0.0)\end{array}$ & $\begin{array}{c}0 \\
(0.0)\end{array}$ & $\begin{array}{c}1 \\
(0.5)\end{array}$ & $\begin{array}{c}0 \\
(0.0)\end{array}$ & $\begin{array}{c}0 \\
(0.0)\end{array}$ \\
\hline & Others $\bullet$ Ostalo & $\begin{array}{c}0 \\
(0.0)\end{array}$ & $\begin{array}{c}0 \\
(0.0)\end{array}$ & $\begin{array}{c}0 \\
(0.0)\end{array}$ & $\begin{array}{c}0 \\
(0.0)\end{array}$ & $\begin{array}{c}0 \\
(0.0)\end{array}$ & $\begin{array}{c}0 \\
(0.0)\end{array}$ & $\begin{array}{c}2 \\
(1.1)\end{array}$ & $\begin{array}{c}1 \\
(0.5)\end{array}$ & $\begin{array}{c}2 \\
(1.1)\end{array}$ & $\begin{array}{c}1 \\
(0.5)\end{array}$ \\
\hline
\end{tabular}

Bold numbers refer to significant difference $(P<0.05) \bullet$ Podebljani brojevi odnose se na statistički značajnu razliku $(\mathrm{P}<0,05)$

132 teeth $(67.3 \%$ of teeth in males) with one canal. However, the prevalence of two canals was higher in males than in females (64 teeth, representing $32.7 \%$ of teeth in males) who had only 44 teeth $(20.6 \%$ of teeth in females) with 2 canals. The difference was statistically significant $(\mathrm{P}=0.007)$. Similarly, there was a significant difference $(\mathrm{P}=0.007)$ in relation to Vertucci classification among both genders with the same percentages applied.

\section{Lateral incisors}

Amongst 214 teeth in females, there were 213 (99.5\%) teeth with one root, and only one tooth $(0.5 \%)$ was found with 2 roots. Similarly, amongst 198 teeth in males, there were $197(99.5 \%)$ teeth with one root, and only one tooth $(0.5 \%)$ was found with 2 roots. No significant differences were observed $(P=1.000)$. One hundred and fifty two $(71.0 \%)$ teeth dvaju kanala bila je veća kod muškaraca (64 zuba, 32,7 \%) negoli kod žena koje su imale samo 44 zuba (20,6 \%) s dvama kanalima. Razlika je bila statistički značajna $(\mathrm{P}=0,007)$. Slično tomu, zabilježena je značajna razlika $(\mathrm{P}=0,007)$ u odnosu prema Vertuccijevoj klasifikaciji za oba spola u jednakom postotku.

\section{Bočni sjekutići}

Među 214 zuba kod žena je bilo 213 (99,5 \%) jednokorijenskih, a samo je jedan $(0,5 \%)$ pronađen $s$ dvama korijenima. Slično tomu, među 198 zuba kod muškaraca bilo je 197 (99,5 \%) zuba s jednim korijenom, a samo je jedan $(0,5$ $\%$ s dvama. Nisu ustanovljene statistički značajne razlike (P $=1,000)$. Ukupno $152(71,0 \%)$ zuba kod žena i $133(67,2$ 
Table 8 Distribution of mandibular teeth (1st and 2nd molars) among both genders according to number of roots, number of canals canal configuration

Tablica 8. Distribucija donjih zuba (1. i 2. kutnjaci) u oba spola prema broju korijena, broju kanala i konfiguraciji kanala

\begin{tabular}{|c|c|c|c|c|}
\hline & \multicolumn{2}{|c|}{$1^{\text {st }}$ molar $\bullet 1$. kutnjak } & \multicolumn{2}{|c|}{$2^{\text {nd }}$ molar $\bullet 2$. kutnjak } \\
\hline & $\mathbf{M}$ & $\mathbf{F}$ & M & F \\
\hline \multicolumn{5}{|c|}{ Number of roots $\bullet$ Broj korijena } \\
\hline 1 root $\cdot 1$ korijen & $\begin{array}{c}0 \\
(0.0) \\
\end{array}$ & $\begin{array}{c}0 \\
(0.0) \\
\end{array}$ & $\begin{array}{c}0 \\
(0.0) \\
\end{array}$ & $\begin{array}{c}2 \\
(1.2) \\
\end{array}$ \\
\hline 2 roots $\bullet 2$ korijena & $145(96.0)$ & $129(92.8)$ & $171(98.8)$ & $\begin{array}{c}157 \\
(95.7) \\
\end{array}$ \\
\hline 3 roots $\bullet 3$ korijena & $\begin{array}{c}6 \\
(4.0)\end{array}$ & $\begin{array}{c}10 \\
(7.2)\end{array}$ & $\begin{array}{c}2 \\
(1.2)\end{array}$ & $\begin{array}{c}5 \\
(3.0)\end{array}$ \\
\hline
\end{tabular}

\begin{tabular}{|c|c|c|c|c|c|c|c|c|c|}
\hline \multicolumn{10}{|c|}{ Number of canals $\bullet$ Broj kanala } \\
\hline \multicolumn{2}{|c|}{1 canal $\bullet 1$ kanal } & & $\begin{array}{c}0 \\
(0.0)\end{array}$ & $\begin{array}{c}0 \\
(0.0)\end{array}$ & & & $\begin{array}{c}0 \\
(0.0)\end{array}$ & $\begin{array}{c}0 \\
(0.0)\end{array}$ & \\
\hline \multicolumn{2}{|c|}{2 canals $\bullet 2$ kanala } & & $\begin{array}{c}1 \\
(0.7)\end{array}$ & $\begin{array}{c}1 \\
(0.7)\end{array}$ & & & $\begin{array}{c}9 \\
(5.2)\end{array}$ & $\begin{array}{c}14 \\
(8.5)\end{array}$ & \\
\hline \multicolumn{2}{|c|}{3 canals $\bullet 3$ kanala } & & $98(64.9)$ & $89(64.0)$ & & & $156(90.2)$ & $\begin{array}{c}138 \\
(84.1)\end{array}$ & \\
\hline \multirow{2}{*}{\multicolumn{2}{|c|}{4 canals $\bullet 4$ kanala }} & & $52(34.4)$ & $49(35.3)$ & & & $\begin{array}{c}8 \\
(4.6)\end{array}$ & $\begin{array}{c}12 \\
(7.3)\end{array}$ & \\
\hline & & \multicolumn{2}{|c|}{ Mesial root } & \multicolumn{2}{|c|}{ Distal root } & \multicolumn{2}{|c|}{ Mesial root } & \multicolumn{2}{|c|}{ Distal root } \\
\hline & & M & F & M & F & M & F & M & F \\
\hline \multirow{8}{*}{ 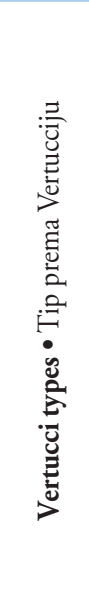 } & Type I • Tip I & $\begin{array}{c}2 \\
(1.3)\end{array}$ & $\begin{array}{c}1 \\
(0.7)\end{array}$ & $103(68.2)$ & $97(69.8)$ & $\begin{array}{c}8 \\
(4.6)\end{array}$ & $\begin{array}{c}13 \\
(7.9)\end{array}$ & $\begin{array}{c}164 \\
(94.8)\end{array}$ & $\begin{array}{c}158 \\
(96.3)\end{array}$ \\
\hline & Type II • Tip II & $48(31.8)$ & $57(41.0)$ & $\begin{array}{c}1 \\
(0.7)\end{array}$ & $\begin{array}{c}8 \\
(5.8)\end{array}$ & $41(23.7)$ & $45(27.4)$ & $\begin{array}{c}0 \\
(0.0)\end{array}$ & $\begin{array}{c}3 \\
(1.8)\end{array}$ \\
\hline & Type III • Tip III & $\begin{array}{c}3 \\
(2.0)\end{array}$ & $\begin{array}{c}1 \\
(0.7)\end{array}$ & $25(16.6)$ & $25(18.0)$ & $26(15.0)$ & $28(17.1)$ & $\begin{array}{c}2 \\
(1.2)\end{array}$ & $\begin{array}{c}1 \\
(0.6)\end{array}$ \\
\hline & Type IV • Tip IV & $93(61.6)$ & $75(54.0)$ & $\begin{array}{c}0 \\
(0.0)\end{array}$ & $\begin{array}{c}2 \\
(1.4)\end{array}$ & $77(44.5)$ & $56(34.1)$ & $\begin{array}{c}0 \\
(0.0)\end{array}$ & $\begin{array}{c}0 \\
(0.0)\end{array}$ \\
\hline & Type V・Tip V & $\begin{array}{c}5 \\
(3.3)\end{array}$ & $\begin{array}{c}5 \\
(3.6)\end{array}$ & $22(14.6)$ & $\begin{array}{c}7 \\
(5.0)\end{array}$ & $21(12.1)$ & $22(13.4)$ & $\begin{array}{c}7 \\
(4.0)\end{array}$ & $\begin{array}{c}2 \\
(1.2)\end{array}$ \\
\hline & Type VI • Tip VI & $\begin{array}{c}0 \\
(0.0)\end{array}$ & $\begin{array}{c}0 \\
(0.0)\end{array}$ & $\begin{array}{c}0 \\
(0.0)\end{array}$ & $\begin{array}{c}0 \\
(0.0)\end{array}$ & $\begin{array}{c}0 \\
(0.0)\end{array}$ & $\begin{array}{c}0 \\
(0.0)\end{array}$ & $\begin{array}{c}0 \\
(0.0)\end{array}$ & $\begin{array}{c}0 \\
(0.0)\end{array}$ \\
\hline & Type VII • Tip VII & $\begin{array}{c}0 \\
(0.0) \\
\end{array}$ & $\begin{array}{c}0 \\
(0.0) \\
\end{array}$ & $\begin{array}{c}0 \\
(0.0) \\
\end{array}$ & $\begin{array}{c}0 \\
(0.0) \\
\end{array}$ & $\begin{array}{c}0 \\
(0.0) \\
\end{array}$ & $\begin{array}{c}0 \\
(0.0) \\
\end{array}$ & $\begin{array}{c}0 \\
(0.0) \\
\end{array}$ & $\begin{array}{c}0 \\
(0.0) \\
\end{array}$ \\
\hline & Others $\bullet$ Ostalo & $\begin{array}{c}0 \\
(0.0)\end{array}$ & $\begin{array}{c}0 \\
(0.0)\end{array}$ & $\begin{array}{c}0 \\
(0.0)\end{array}$ & $\begin{array}{c}0 \\
(0.0)\end{array}$ & $\begin{array}{c}0 \\
(0.0)\end{array}$ & $\begin{array}{c}0 \\
(0.0)\end{array}$ & $\begin{array}{c}0 \\
(0.0)\end{array}$ & $\begin{array}{c}0 \\
(0.0)\end{array}$ \\
\hline
\end{tabular}

Bold numbers refer to significant difference $(P<0.05) \bullet$ Podebljani brojevi odnose se na statistički značajnu razliku $(\mathrm{P}<0,05)$

in females and $133(67.2 \%)$ in males had one canal, while $62(29.0 \%)$ teeth in females and $65(32.8 \%)$ teeth in males had 2 canals, with no significant differences $(P=0.455)$. Regarding Vertucci classification, $133(67.2 \%)$ teeth in males had Vertucci type I, 63 (31.8\%) teeth had Vertucci type III, and only $2(1.0 \%)$ teeth had Vertucci type V. In females, 152 $(71.0 \%)$ teeth had Vertucci type I, 60 (28.0\%) teeth had Vertucci type III, and only $2(1.0 \%)$ teeth had Vertucci type V. No significant differences were found between both genders $(P=0.698)$.

\section{Canines}

Amongst 197 mandibular canines in males, there were $195(99.0 \%)$ with one root and $2(1.0 \%)$ teeth with 2 roots, while amongst 213 mandibular canines in females there were $204(95.8 \%)$ teeth with one root, and 9 (4.2\%) teeth with 2 roots. No significant differences were found between both genders $(P=0.064)$. One hundred and eighty four $(93.4 \%)$ mandibular canines in males had one canal, while 188 $(88.3 \%)$ mandibular canines in females had one canal. No
\%) kod muškaraca imalo je jedan kanal, a $62(29,0 \%)$ zuba kod žena i $65(32,8 \%)$ kod muškaraca imala su dva kanala, bez značajne razlike $(\mathrm{P}=0,455)$. Kad je riječ o Vertuccijevoj klasifikaciji, 133 (67,2 \%) zuba kod muškaraca pripadalo je tipu I, $63(31,8 \%)$ tipu III, a samo dva (1,0 \%) tipu V. Kod žena su $152(71,0 \%)$ zuba pripadala Vertuccijevu tipu I, 60 $(28,0 \%)$ tipu III, a samo dva (1,0 \%) tipu V. Nisu ustanovljene značajne razlike između spolova $(\mathrm{P}=0,698)$.

\section{Očnjaci}

Između 197 donjih očnjaka kod muškaraca bilo je 195 $(99,0 \%)$ s jednim korijenom i dva (1,0 \%) zuba s dvama korijenima, a od 213 donjih očnjaka kod žena njih $204(95,8$ $\%)$ bilo je $s$ jednim korijenom, a dva $s$ devet $(4,2 \%)$.. Nisu ustanovljene značajne razlike između spolova $(\mathrm{P}=0,064)$. Ukupno 184 (93,4 \%) donja očnjaka kod muškaraca bila su jednokanalna, a 188 (88,3 \%) zabilježeno ih je kod žena. Nisu ustanovljene značajne razlike između spolova $(\mathrm{P}=0,088)$. 
significant differences were observed between both genders $(P=0.088)$. Vertucci type I was more frequent in males than in females (93.4\% compared to $88.3 \%$ ), while Vertucci types III and V were more frequent in females than in males. The significant level of difference between both genders was near the cut-off point $(P=0.049)$.

\section{First premolars}

Although the prevalence of teeth with one root was higher in females than in males (100\% compared to $98.9 \%)$, no significant differences between both genders was found $(P=$ $0.224)$. Similarly, no significant differences $(P=0.229)$ were found between both genders with regard to the number of canals. However, a significant difference $(P=0.012)$ was found between both genders in relation to canal configuration. The teeth with Vertucci types I and V had higher prevalence in females than in males, while the teeth with Vertucci type III had higher prevalence in males.

\section{Second premolars}

Regarding comparison between genders, all teeth (100.0\%) in males and all teeth $(100.0 \%)$ in females had one root. No significant differences $(P=0.055)$ were found between both genders with regard to the number of canals although the prevalence of teeth with one canal was higher in females compared to males (99.0\% compared to $94.7 \%$, respectively). Similarly, no significant differences $(P=0.098)$ were found in relation to canal configuration. Nevertheless, the prevalence of the teeth with Vertucci type I in females was $189(99.0 \%)$ compared to their male counterparts, $178(94.7 \%)$.

\section{First molars}

Most teeth in both genders had 2 roots and 3 canals with no significant differences $(P=0.305$ and $P=0.987$, respectively). Similarly, no significant differences $(P=0.471)$ were found between both genders with regard to Vertucci types in mesial canals. However, a significant difference $(P=0.005)$ was found between both genders in relation to Vertucci types in distal canals, with higher prevalence of Vertucci types II and III in females and Vertucci type V in males.

\section{Second molars}

No significant differences were found between both genders in relation to the number of roots $(P=0.162$, with higher prevalence of teeth with 2 roots in males), the number of canals $(P=0.253$, with higher prevalence of teeth with $3 \mathrm{ca}$ nals in males), Vertucci types in mesial canals $(P=0.336$, with higher prevalence of teeth with Vertucci type IV in males and Vertucci type II in females), and Vertucci types in distal canals $(P=0.112$, with higher prevalence of teeth with Vertucci type I in females). The prevalence of $\mathrm{C}$-shaped canal configuration was found in 29 cases out of 367 teeth (7.9\%) in mandibular second molars with no significant differences found between both genders

\section{Discussion}

Over the past few years, various techniques have been developed to study root canal morphology including CBCT which has increased in popularity nowadays although the micro-CT evaluates the root canal morphology with high resolution, thus producing accurate results. This technique, how-
Vertuccijev tip I bio je češći kod muškaraca negoli kod žena (93,4 \% u usporedbi s $88,3 \%$ ), a tipovi III i V bili su češći kod žena negoli kod muškaraca. Značajnost razlike između obaju spolova bila je granična $(P=0,049)$.

\section{Prvi pretkutnjaci}

Iako je prevalencija zuba $s$ jednim korijenom bila veća kod žena negoli kod muškaraca (100 \% u usporedbi s 98,9 $\%$, nisu ustanovljene značajne razlike između spolova ( $\mathrm{P}=$ $0,224)$. Slično tomu, nisu ustanovljene značajne razlike $(\mathrm{P}=$ $0,229)$ između spolova s obzirom na broj kanala. No pronađena je značajna razlika $(P=0,012)$ između spolova u odnosu prema konfiguraciji kanala. Zubi s Vertuccijvim tipom I i $\mathrm{V}$ češće su pronađeni kod žena negoli kod muškaraca, a zubi s tipom III imali su veću prevalenciju kod muškaraca.

\section{Drugi pretkutnjaci}

U usporedbi spolova, svi zubi (100,0 \%) kod muškaraca i svi zubi $(100,0 \%)$ kod žena imali su jedan korijen. Nisu ustanovljene značajne razlike $(\mathrm{P}=0,055)$ između spolova $s$ obzirom na broj kanala, iako je prevalencija zuba s jednim kanalom bila veća kod žena u usporedbi s muškarcima $(99,0$ $\%$ prema 94,7 \%). Slično tomu, nisu ustanovljene značajne razlike u odnosu prema konfiguraciji kanala $(P=0,098)$. Unatoč tomu, prevalencija zuba s Vertuccijevim tipom I kod žena iznosila je 189 (99,0 \%) u usporedbi sa 178 (94,7\%) kod muškaraca.

\section{Prvi kutnjaci}

Većina zuba u oba spola imala je dva korijena i tri kanala, bez značajnih razlika $(\mathrm{P}=0,305 \mathrm{i} \mathrm{P}=0,987)$. Slično tomu, nisu ustanovljene značajne razlike $(\mathrm{P}=0,471)$ između spolova $s$ obzirom na Vertuccijeve tipove u mezijalnim kanalima. No pronađena je značajna razlika $(\mathrm{P}=0,005)$ između spolova u odnosu prema Vertuccijevim tipovima u distalnim kanalima, s većom prevalencijom tipova II i III kod žena i tipa $\mathrm{V}$ kod muškaraca.

\section{Drugi kutnjaci}

Nije ustanovljena značajna razlika između spolova u odnosu prema broju korijena $(\mathrm{P}=0,162$, $s$ većom prevalencijom zuba s dvama korijenima kod muškaraca), broj kanala ( $\mathrm{P}$ $=0,253, \mathrm{~s}$ većom prevalencijom zuba $\mathrm{s}$ trima kanalima kod muškaraca), Vertuccijeve tipove u mezijalnim kanalima ( $\mathrm{P}=$ $0,336, s$ većom prevalencijom zuba s tipom IV kod muškaraca i tipom II kod žena) te istoimene tipove u distalnim kanalima $(\mathrm{P}=0,112$, $s$ većom prevalencijom zuba $s$ tipom I kod žena). U 29 slučajeva od 367 zuba (7,9\%) u drugom donjem kutnjaku ustanovljena je prevalencija C-oblika kanala za koji nisu pronađene značajne razlike između spolova.

\section{Rasprava}

Tijekom posljednjih nekoliko godina pojavile su se razne tehnike za proučavanje morfologije korijenskog kanala, uključujući CBCT koji je danas sve popularniji, iako i mikro CT prikazuje morfologiju korijenskog kanala s visokom razlučivošću i daje točne rezultate. No ta tehnika nije toliko 
ever, does not work well in daily practice settings to examine patients (34), whereas CBCT, compared to other techniques, is a clinically non-invasive tool being used in daily practice which, apart from being reliable, accurately detects root canal anatomy $(34,35)$. In-vivo CBCT is a great tool for retrospective prevalence studies because a big number of patients could be examined safely. Therefore, this tool was chosen for this study to provide a large number of teeth with known genders for a more reliable outcome. Also, in this study, we overcame the problem of exposing the subjects to unnecessary radiation doses by retrieving old records from the database and by using a voxel size $0.25 \mu \mathrm{m}$ of the CBCT machine, which is similar to another in-vivo $\mathrm{CBCT}$ study which has evaluated the root anatomy of all groups of teeth successfully (21).

In the present study, a comparison between males and females regarding the number of roots, the number of root canals, and root canal configurations according to Vertucci's classification was performed. Regarding the number of roots, no significant differences were found between genders in all 14 groups of teeth. This is in agreement with an in-vivo CBCT study of all permanent dentition in a Malaysian subpopulation (21). However, another comprehensive in-vivo CBCT study in a Portuguese population reported significant differences between genders in four of 14 tooth groups with females who had a smaller numbers of roots per tooth in maxillary first premolars, and second molars, while mandibular canines showed the opposite (19). In a Saudi population, anatomical studies using in-vivo CBCT are consistent with our findings with no significant differences between genders in the number of roots of maxillary premolars (27), maxillary first molars (26), mandibular canines (29), and mandibular first molars (28). Another two in-vivo CBCT studies in different populations reported some significant differences between genders in number of roots of maxillary and mandibular first and second premolars, where they found that males had higher prevalence of 2-rooted premolars, while females had higher prevalence of single-rooted premolars (36,37). Also, similar results were obtained in other CBCT studies on maxillary and mandibular molars, where females had lower prevalence of roots compared to males $(32,33,38)$. In the literature, there is a tendency of females to have a smaller number of roots per tooth while, many studies, however, support that there were some CBCT studies reported otherwise but with no significant differences $(23,31,32)$.

Generally, the internal canal morphology follows the external anatomy of the root (39), and that might have an impact on a smaller number of roots in different genders. In regards to the number of canals in the present study, only 3 groups out of 14 teeth groups (two in maxillary teeth and one in mandibular teeth) showed significant differences between genders. Maxillary first and second molars had 4 canals with higher percentages in males than in females. However, in mandibular teeth groups, only central incisors showed statistically significant differences $(P=0.007)$, where males had a larger number of teeth with 2 canals compared to females. In a study of all permanent dentition in a Malaysian subpopulation (21), only 2 groups of teeth (second premolars and primjenjiva u svakodnevnoj praksi za dijagnostiku (34), dok je CBCT, u usporedbi s drugim tehnikama, klinički neinvazivan uređaj koji, uz to što je pouzdan, točno prikazuje anatomiju korijenskog kanala $(34,35)$. CBCT in vivo sjajan je alat za retrospektivna istraživanja prevalencije jer se velik broj pacijenata može sigurno pregledati. Zato je i odabran za ovo istraživanje kako bi se osigurao što veći broj zuba za što pouzdaniji rezultat. $\mathrm{U}$ ovom istraživanju također smo premostili i problem izlaganja subjekata nepotrebnim dozama zračenja povlačenjem starih zapisa iz baze podataka i korištenjem voksela veličine $0,25 \mu \mathrm{m}$ CBCT uređaja, što je slično drugom istraživanju in vivo s pomoću CBCT-a u kojemu su autori uspješno procijenili anatomiju korijena svih skupina zuba (21).

U ovom istraživanju uspoređeni su muškarci i žene u broju korijena, broju korijenskih kanala i u konfiguraciji korijenskog kanala prema Vertuccijevoj klasifikaciji. Kad je riječ o broju korijena, nisu ustanovljene statistički značajne razlike između spolova u svih 14 skupina zuba. To je u skladu s istraživanjem in vivo na temelju CBCT-a svih trajnih zuba u malezijskoj potpopulaciji (21). No u drugom sveobuhvatnom istraživanju in vivo s pomoću CBCT-a u portugalskoj populaciji, uočene su značajne razlike između spolova u četiri od 14 skupina zuba, pri čemu su žene imale manji broj korijena po zubu u prvim gornjim pretkutnjacima i drugim kutnjacima, a s donjim očnjacima bilo je suprotno (19). U populaciji Saudijske Arabije anatomska istraživanja koja se provode CBCT-om in vivo u skladu su s našim nalazima, bez značajnih razlika između spolova u broju korijena gornjih pretkutnjaka (27), prvih gornjih kutnjaka (26), donjih očnjaka (29) i prvih donjih kutnjaka (28). U dvama istraživanjima in vivo s pomoću CBCT-a u različitim populacijama istaknute su značajne razlike između spolova u broju korijena prvoga i drugoga gornjeg pretkutnjaka, pri čemu je otkriveno da muškarci imaju veću prevalenciju dvokorijenskih pretkutnjaka, a žene jednokorijenskih pretkutnjaka $(36,37)$. Slični rezultati dobiveni su i u ostalim istraživanjima na temelju CBCT-a na gornjim i donjim kutnjacima - u svima su žene imale manji broj korijena u usporedbi s muškarcima $(32,33,38)$. U literaturi postoji tendencija da žene imaju manji broj korijena po zubu, iako se u mnogim istraživanjima na temelju CBCT-a ističe suprotno, ali bez statistički značajnih razlika $(23,31,32)$.

Općenito, morfologija kanalnog sustava slijedi vanjsku anatomiju korijena (39), a to bi moglo utjecati na različit broj korijena među spolovima. $S$ obzirom na broj kanala u ovom istraživanju, samo su tri od 14 skupina zuba (dvije gornjih zuba i jedna donjih zuba) pokazale statistički značajne razlike između spolova. Gornji prvi i drugi kutnjaci imali su četiri kanala $s$ većim postotkom kod muškaraca negoli kod žena. No u skupinama donjih zuba samo su središnji sjekutići pokazali statistički značajne razlike $(\mathrm{P}=0,007)$, pri čemu su muškarci imali veći broj zuba s dvama kanalima u odnosu prema ženama. U istraživanju svih trajnih zuba u malezijskoj subpopulaciji (21), samo su u dvjema skupinama zuba (drugi pretkutnjaci i drugi kutnjaci) muškarci imali statistički značajno veći broj kanala u odnosu prema ženama, a u ostalim skupinama zuba nisu zabilježene značajnije razlike. U nekim istraživanjima provedenima na populaciji Saudijske Ara- 
second molars) showed that males had a significantly larger number of canals compared to females, while the rest of teeth groups had no significant differences. In a Saudi population, some studies reported similar results to our findings, where in maxillary first molars males had a significantly larger number of canals compared to females (26). However, other studies reported that there were no significant differences between genders regarding maxillary premolars, mandibular canines, and mandibular first molars $(27,29)$.

In the present study, we also investigated the association between genders with RCS configurations. In total, maxillary teeth showed highly statistically significant differences $(\mathrm{P}<0.001)$ between both genders with regard to canals configurations where, roots with Vertucci type II, IV, VI, and VII were more frequent in males than in females, while the roots with Vertucci type I, III, and V were more frequent in females. However, only 2 groups (first premolars and second molars) out of 7 teeth groups of maxillary teeth showed statistically significant differences between both genders in relation to canal configurations. These findings are generally consistent with a study performed in a Portuguese population where all teeth showed higher prevalences of Vertucci type I configurations in females, which is highly statistically significant in both maxillary premolars (19). However, in a Malaysian subpopulation there were no statistically significant differences between genders regarding RCS configurations in all teeth groups (21). In addition, a study of maxillary first premolars in a Saudi population (27) showed no differences between genders regarding the canal configuration, while the findings of German subpopulation study (36) are in agreement with our results where Vertucci type I for maxillary first premolars had higher prevalence in females. Another study in a Korean population (7) on maxillary second molars, mesial buccal roots, showed similar canal configurations compared to our study with higher prevalence of Vertucci type I in females. However, the differences were not statistically significant. In contrast, other studies in different populations reported (with no significant differences) higher prevalence of Vertucci type I in mesial buccal roots of both maxillary molars in males compared to females $(32,40)$. The differences in findings of the above mentioned studies might be related to ethnic background and/or sample size.

In mandibular teeth, generally, there were significant differences between males and females in relation to the canal configuration of anterior and premolar teeth $(\mathrm{P}=0.016)$, and distal roots of first and second molars together $(\mathrm{P}<0.001)$. Specifically, only three groups out of seven teeth groups showed statistically significant differences between genders in regards to canal configurations. The prevalence of Vertucci type I canal configuration was significantly higher in females in mandibular central incisors and first premolars, whereas in distal roots of mandibular first molars, the prevalence of Vertucci types II and III was highly significant in females and Vertucci type V in males. In a Portuguese study (19), the results showed differences in five of the seven groups of mandibular teeth with a higher tendency for Vertucci type I in females, while in central incisors and first premolars the differences were significant with females who had higher prev- bije dobiveni su rezultati slični našima - muškarci su u prvim gornjim kutnjacima imali značajno veći broj kanala u odnosu prema ženama (26). No u drugim je istraživanjima istaknuto da nema značajnih razlika između spolova kad je riječ o gornjim pretkutnjaciuma, donjim očnjacima i prvim donjim kutnjacima $(27,29)$.

U ovom istraživanju također smo istražili povezanost spola i konfiguracije kanalnog sustava. Sveukupno, gornji zubi pokazali su statistički visoko značajne razlike $(\mathrm{P}<0,001)$ između obaju spolova s obzirom na konfiguraciju kanala te su korijeni s Vertuccijevim tipovima II, IV, VI i VII bili češći kod muškaraca negoli kod žena, a korijeni s tipovima I, III i V bili su češći kod žena. No samo dvije (prvi pretkutnjaci i drugi kutnjaci) od sedam skupina gornjih zuba pokazale su statistički značajne razlike između spolova s obzirom na konfiguraciju kanala. Ti nalazi općenito su u skladu s istraživanjem provedenim u portugalskoj populaciji kod koje su svi zubi pokazali veću prevalenciju tipa I prema Vertucciju kod žena, što je statistički značajna razlika u oba gornja pretkutnjaka (19). No u malezijskoj subpopulaciji nije bilo statistički značajnih razlika između spolova u konfiguraciji kanalnih sustava u svim skupinama zuba (21). Uz to, istraživanje prvih gornjih pretkutnjaka u populaciji Saudijske Arabije (27) nije pokazalo razlike između spolova u konfiguraciji kanala, a nalazi njemačkoga subpopulacijskog istraživanja (36) u skladu su s našim rezultatima u kojima je Vertuccijev tip I za prve gornje pretkutnjake imao veću prevalenciju kod žena. U drugom istraživanju na korejskoj populaciji (7) na drugim gornjim kutnjacima, mezijalni bukalni korijeni imali su slične konfiguracije kanala u usporedbi $s$ našim istraživanjem $s$ većom prevalencijom Vertuccijeva tipa I kod žena. No razlike nisu bile statistički značajne. Suprotno tomu, u drugim istraživanjima u različitim populacijama zabilježena je veća prevalencija (bez značajnih razlika) Vertuccijeva tipa I u mezijalnim bukalnim korijenima obaju gornjih kutnjaka kod muškaraca u usporedbi sa ženama $(32,40)$. Razlike u nalazima navedenih istraživanja mogu biti povezane s etničkim podrijetlom i/ili veličinom uzorka.

U donjim zubima općenito su postojale značajne razlike između muškaraca i žena u odnosu prema konfiguraciji kanala prednjih zuba i pretkutnjaka $(\mathrm{P}=0,016)$ te distalnih korijena prvoga i drugoga kutnjaka $(\mathrm{P}<0,001)$. Naime, samo su tri od sedam skupina zuba pokazale statistički značajne razlike između spolova u konfiguraciji kanala. Prevalencija konfiguracije kanala tipa I prema Vertucciju bila je značajno veća kod žena na donjim središnjim sjekutićima i prvim pretkutnjacima, a u distalnim korijenima prvih donjih kutnjaka prevalencija tipova II i III bila je visoko značajna kod žena i tipa $\mathrm{V}$ kod muškaraca. $\mathrm{U}$ portugalskom istraživanju (19) rezultati su pokazali razlike u pet od sedam skupina donjih zuba s većom tendencijom tipa I prema Vertucciju kod žena, a u središnjim sjekutićima i prvim pretkutnjacima razlike su bile značajne kod žena koje su imale veću prevalenciju tipa I. Kad je riječ o očnjacima, muškarci su imali statistički značajno veću prevalenciju tipa I prema Vertucciju. Ti rezultati uglavnom su u skladu s našim nalazima. $U$ drugom sveobuhvatnom istraživanju na temelju CBCT-a (21) autori nisu pronašli statistički značajne razlike između spolova u 
alence of Vertucci type I. Regarding canines, males had a significantly higher prevalence of Vertucci type I. These results are generally in agreement with our findings. In another comprehensive CBCT study (21), the authors found no statistical differences between genders regarding canal configuration, except that females had a significantly higher prevalence of second molar teeth with C-shaped morphology, while in our study, mandibular second molars with C-shaped canals had no gender association. In a Saudi population, the prevalence of Vertucci type I in mandibular canines in female patients was significantly higher than in males (29), which is contrary to our findings where no statistical differences between genders were found. Another study (28) in the same population on mandibular first molars showed no association between genders and canal configurations, whereas our study showed a significant difference in distal roots canal systems, with higher prevalence of Vertucci types II and III in females and Vertucci type $\mathrm{V}$ in males. These inconsistencies between studies in the same Saudi population could be related to the region in the same country where the sample was obtained and the sample size. In addition, studies from different populations showed that females have higher percentage of Vertucci type I compared to males in mandibular central incisors (25) and first premolars (41). All the above mentioned studies were in-vivo $\mathrm{CBCT}$ anatomical studies addressing gender differences related to roots and root morphology.

The present in-vivo CBCT study is the first comprehensive study conducted in a Saudi Arabian population evaluating all teeth groups in the same individuals with a large sample. The results from the available literature led to a hypothesis that males tend to have a larger number of roots and root canals than females regardless of the statistical significance of the results. However, previous studies that were performed on specific teeth groups might not have observed this tendency (19). So far, only 3 studies $(19,21)$ including our study which used in-vivo CBCT on all teeth groups have partially accepted this hypothesis. Other in-vivo CBCT studies are recommended on all teeth groups in different populations with a large sample, adding to the present ones, which could either support the global tendency that is mentioned in the hypothesis or prove that the differences exist only in the specific group(s) of teeth.

\section{Conclusion}

Within the limitations of the present study, the following conclusions could be drawn: No significant differences in relation to the number of roots between both genders were found. Significant differences with regard to number of canals were detected only in three groups out of 14 groups of teeth with females having a smaller number of canals; In relation to canal configuration, two groups of maxillary teeth and three groups of mandibular teeth showed statistically significant differences between both genders.

\section{Conflict of interest}

None declared konfiguraciji kanala, osim što su žene imale značajno veću prevalenciju morfologijom u C-obliku drugoga kutnjaka, a u našem istraživanju drugi donji kutnjaci s C-konfiguracijom nisu imali spolnu povezanost. U populaciji Saudijske Arabije prevalencija tipa I prema Vertucciju u donjim očnjacima bila je značajno veća kod žena negoli kod muškaraca (29), što je suprotno našim nalazima u kojima nisu pronađene statistički značajne razlike među spolovima. U drugom istraživanju (28) na istoj populaciji na prvim donjim kutnjacima nije se pokazala povezanost spolova i konfiguracije kanala, a u našem se istraživanju uočila statistički značajna razlika u kanalnim sustavima distalnih korijena, s većom prevalencijom Vertuccijevih tipova II i III kod žena i tipa V kod muškaraca. Te razlike između istraživanja u istoj populaciji mogu biti posljedica različitih regija u istoj zemlji u kojoj je uzorak dobiven i veličine uzorka. $U z$ to, istraživanja u različitim populacijama pokazala su da žene imaju veći postotak Vertuccijeva tipa I u usporedbi s muškarcima u donjim središnjim sjekutićima (25) i prvim pretkutnjacima (41). Sva navedena istraživanja provedena su in vivo analizom CBCT-a i bavila su se rodnim razlikama morfologije korijena.

Ovo istraživanje in vivo na temelju CBCT-a prvo je sveobuhvatno istraživanje provedeno na populaciji Saudijske Arabije u kojemu su se procjenjivale sve skupine zuba istih osoba na velikom uzorku. Rezultati dostupne literature doveli su do hipoteze da muškarci imaju veći broj korijena i korijenskih kanala od žena, bez obzira na statističku značajnost rezultata. No dosadašnja istraživanja koja su provedena na specifičnim skupinama zuba možda nisu pokazala tu tendenciju (19). Dosad su samo tri istraživanja $(19,21)$, uključujući i naše koje se koristilo CBCT-om in vivo na svim skupinama zuba, djelomično prihvatila tu hipotezu. Preporučuju se dodatna istraživanja in vivo na temelju CBCT-a na svim skupinama zuba u različitim populacijama s velikim uzorkom koja bi mogla potvrditi tendenciju koja se spominje u hipotezi ili dokazati da razlike postoje samo u određenim skupinama zuba.

\section{Zaključak}

Uzimajući u obzir ograničenja ovog istraživanja može se zaključiti sljedeće: nisu pronađene statistički značajne razlike između spolova u odnosu prema broju korijena. Značajne razlike s obzirom na broj kanala ustanovljene su samo u trima od 14 skupina zuba kod žena koje imaju manji broj kanala. $\mathrm{U}$ odnosu prema konfiguraciji kanala, dvije skupine gornjih zuba i tri skupine donjih zuba pokazale su statistički značajne razlike između spolova.

\section{Sukob interesa}

Autori nisu bili u sukobu interesa. 
Sažetak

Svrha: Željele su se sveobuhvatno istražiti razlike među trajnim gornjim i donjim zubima u odnosu prema broju korijena, broj korijenskih kanala i njihova konfiguracija između spolova u populaciji Saudijske Arabije. Ispitanici i metode: Ovo retrospektivno radiološko istraživanje obuhvatilo je 208 is pitanika (48 \% muškaraca i 52 \% žena) prosječne dobi 28,74 $\pm 9,56$ godina. CBCT snimke ispitanika evaluirane su za sve trajne zube. Detaljna analiza obavljena je optimalnom vizualizacijom svih softverskih značajki. Podatci su analizirani s pomoću programa SPSS. Cohenov Kappa test korišten je za analizu pouzdanosti, a Chi-kvadrat test za analizu razlika između spolova u odnosu prema varijablama. P-vrijednost <0,05 smatrala se statistički značajnom. Rezultati: Ukupno su procijenjena 5254 trajna gornja i donja zuba. U odnosu prema broju korijena nisu ustanovljene statistički značajne razlike između spolova za sve gornje i donje zube zajedno $(P=0,064)$, ni za gornje ili donje zube odvojeno $(P=0,315$ i $P=0,100)$. Ustanovljena je statistički značajna razlika između muškaraca i žena u odnosu prema broju kanala u gornjim zubima $(P=0,014)$. Za donje zube značajnost razlike bila je granična $(P=0,050)$. Za sve gornje i donje zube distribucija između spolova nije bila statistički značajna ( $P=0,082)$. Razlika između spolova, s obzirom na konfiguraciju kanala korijena gornjih zuba, bila je statistički značajna $(P<0,001)$. Za donje zube razlika između muškaraca i žena u odnosu prema konfiguraciji kanala prednjih zuba i pretkutnjaka bila je statistički značajna $(P=0,016)$, a nije bila značajna za mezijalne korijene prvoga i drugoga kutnjaka $(P=0,205)$. No razlika je bila značajna za distalne korijene prvoga i drugoga kutnjaka $(P<0,001)$. Zaključak: Nije ustanovljena statistički značajna razlika između spolova u odnosu prema broju korijena. Kada je riječ o broju kanala, značajne razlike pronađene su samo u trima od 14 skupina zuba kod žena koje su imale manji broj kanala negoli muškarci. Kad je riječ o konfiguraciji kanala, dvije skupine gornjih zuba i tri skupine donjih pokazale su statistički značajne razlike između spolova.
Zaprimljen: 24. svibnja 2019.

Prihvaćen: 27. srpnja 2019.

Adresa za dopisivanje

Mohammed Mashyakhy

Department of Restorative Dental

Sciences

College of Dentistry, Jazan University

Jazan, Kingdom of Saudi Arabia,

P.O Box 114

dr.mashyakhy@gmail.com

Ključne riječi

korijen zuba; komora zubne pulpe; anatomija zuba

\section{References}

1. Goyal G, Singh R, Bansal N, Paliwal VK. Anatomical Variations of Cerebral MR Venography: Is Gender Matter? Neurointervention. 2016 Sep;11(2):92-8.

2. Clayton JA. Sex influences in neurological disorders: case studies and perspectives. Dialogues Clin Neurosci. 2016 Dec;18(4):357360.

3. Fan H, Zhao G, Ren D, Liu F, Dong G, Hou Y. Gender differences of $B$ cell signature related to estrogen-induced IFI44L/BAFF in systemic lupus erythematosus. Immunol Lett. 2017 Jan;181:71-78.

4. Zissimopoulos JM, Barthold D, Brinton RD, Joyce G. Sex and Race Differences in the Association Between Statin Use and the Incidence of Alzheimer Disease. JAMA Neurol. 2017 Feb 1;74(2):225-232.

5. Brar A, Markell M. Impact of gender and gender disparities in patients with kidney disease. Curr Curr Opin Nephrol Hypertens. 2019 Mar;28(2):178-182.

6. Martins JNR, Mata A, Marques D, Anderson C, Caramês J. Prevalence and characteristics of the maxillary C-shaped molar. J Endod. 2016 Mar;42(3):383-9.

7. Kim Y, Lee S-J, Woo J. Morphology of maxillary first and second molars analyzed by cone-beam computed tomography in a korean population: variations in the number of roots and canals and the incidence of fusion. J Endod. 2012 Aug;38(8):1063-8.

8. Khammissa RA, Meer S, Lemmer J, Feller L. Oral squamous cell carcinoma in a South African sample: Race/ethnicity, age, gender, and degree of histopathological differentiation. J Cancer Res Ther. 2014 Oct-Dec;10(4):908-14.

9. Kadashetti V, Chaudhary M, Patil S, Gawande M, Shivakumar KM, Patil S, et al. Analysis of various risk factors affecting potentially malignant disorders and oral cancer patients of Central India. Cancer Res Ther. 2015 Apr-Jun;11(2):280-6.

10. Vertucci FJ. Root canal anatomy of the human permanent teeth. Oral Surg Oral Med Oral Pathol. 1984;58(5):589-99.

11. Weine FS, Pasiewicz RA, Rice RT. Canal configuration of the mandibular second molar using a clinically oriented in vitro method. Endod. 1988;14(5):207-13.

12. Wong M. Four root canals in a mandibular second premolar. J Endod. 1991;17(3):125-6.

13. Wong M. Maxillary first molar with three palatal canals. J Endod. 1991;17(6):298-9.

14. Gulabivala K, Aung TH, Alavi A, Ng YL. Root and canal morphology of Burmese mandibular molars. Int Endod J. 2001 Jul;34(5):359-70.

15. Ng YL, Aung TH, Alavi A, Gulabivala K. Root and canal morphology of Burmese maxillary molars. Int Endod J. 2001 Dec;34(8):620-30.

16. Gulabivala K, Opasanon A, Ng YL, Alavi A. Root and canal morphology of Thai mandibular molars. Int Endod J. 2002 Jan;35(1):56-62.

17. Kartal N, Yanikoglu F. The incidence of mandibular premolars with more than one root canal in a Turkish population. J Marmara Univ Dent Fac. 1992 Sep;1(3):203-10.
18. Caliskan MK, Pehlivan Y, Sepetcioglu F, Turkun M, Tuncer SS. Root canal morphology of human permanent teeth in a Turkish population. J Endod. 1995 Apr;21(4):200-4.

19. Martins JNR, Marques D, Francisco H, Caramês J. Gender influence on the number of roots and root canal system configuration in human permanent teeth of a Portuguese subpopulation. Quintessence Int. 2018;49(2):103-111.

20. Sert S, Bayirli GS. Evaluation of the root canal configurations of the mandibular and maxillary permanent teeth by gender in the Turkish population. J Endod. 2004 Jun;30(6):391-8.

21. Pan JYY, Parolia A, Chuah SR, Bhatia S, Mutalik S, Pau A. Root canal morphology of permanent teeth in a Malaysian subpopulation using cone-beam computed tomography. BMC Oral Health. 2019 Jan 14;19(1):14.

22. Guo J, Vahidnia A, Sedghizadeh P, Enciso R. Evaluation of root and canal morphology of maxillary permanent first molars in a North American population by cone-beam computed tomography. J Endod. 2014 May;40(5):635-9.

23. Abella F, Teixido LM, Patel S, Sosa F, Duran-Sindreu F, Roig M. Cone-beam Computed Tomography Analysis of the Root Canal Morphology of Maxillary First and Second Premolars in a Spanish Population. J Endod. 2015 Aug;41(8):1241-7.

24. Zheng Q, Wang Y, Zhou X, Wang Q, Zheng G, Huang D. A conebeam computed tomography study of maxillary first permanent molar root and canal morphology in a Chinese population. J Endod. 2010 Sep;36(9):1480-4.

25. Arslan H, Ertas H, Tarim Ertas E, Kalabalik F, Saygili G, Davut Capar I. Evaluating root canal configuration of mandibular incisors with cone-beam computed tomography in a Turkish population. J Dent Sci. 2015;10(4):359-64.

26. Al-Shehri S, Al-Nazhan S, Shoukry S, Al-Shwaimi E, Al-Sadhan $\mathrm{R}$, Al-Shemmery B. Root and canal configuration of the maxillary first molar in a Saudi subpopulation: A cone-beam computed tomography study. Pak J Med Sci. 2015 Mar-Apr;31(2):426-30.

27. Alqedairi A, Alfawaz H, Al-Dahman Y, Alnassar F, Al-Jebaly A, Alsubait S. Cone-Beam Computed Tomographic Evaluation of Root Canal Morphology of Maxillary Premolars in a Saudi Population. Biomed Res Int. 2018 Aug 15; 2018:8170620.

28. Mashyakhy M, Chourasia HR, Halboub E, Almashraqi AA, Khubrani Y, Gambarini G. Anatomical variations and bilateral symmetry of roots and root canal system of mandibular first permanent molars in Saudi Arabian population utilizing cone- beam computed tomography. Saudi Dent J. 2019 (In press).

29. Yousef Al-Dahman, Abdullah Alqedairi1, Hussam Alfawaz1, Faisal Alnassar2 AA. Cone-beam computed tomographic evaluation of root canal morphology of mandibular canines in a Saudi subpopulation. Saudi Endod I. 2019;9:113-8.

30. Alfawaz H, Alqedairi A, Alkhayyal AK, Almobarak AA, Alhusain MF, Martins JNR. Prevalence of C-shaped canal system in mandibular 
first and second molars in a Saudi population assessed via cone beam computed tomography: a retrospective study. Clin Oral Investig. 2019 Jan;23(1):107-112.

31. Kim S-Y, Kim BS, Woo J, Kim Y. Morphology of mandibular first molars analyzed by cone-beam computed tomography in a Korean population: variations in the number of roots and canals. J Endod. 2013 Dec;39(12):1516-21.

32. Altunsoy M, Ok E, Gulsum Nur B, Sami Aglarci O, Gungor E, Colak $M$. Root canal morphology analysis of maxillary permanent first and second molars in a southeastern Turkish population using cone-beam computed tomography. J Dent Sci. 2015;10(4):401-7.

33. Kim SY, Kim BS, Kim Y. Mandibular second molar root canal morphology and variants in a Korean subpopulation. Int Endod J. 2016 Feb;49(2):136-44.

34. Zhang D, Chen J, Lan G, Li M, An J, Wen X, et al. The root canal morphology in mandibular first premolars: a comparative evaluation of cone-beam computed tomography and micro-computed tomography. Clin Oral Investig. 2017 May;21(4):1007-1012.

35. Michetti J, Maret D, Mallet J-P, Diemer F. Validation of cone beam computed tomography as a tool to explore root canal anatomy. J Endod. 2010 Jul;36(7):1187-90.

36. Burklein S, Heck R, Schafer E. Evaluation of the Root Canal Anatomy of Maxillary and Mandibular Premolars in a Selected German
Population Using Cone-beam Computed Tomographic Data. J Endod. 2017 Sep;43(9):1448-1452.

37. Bulut DG, Kose E, Ozcan G, Sekerci AE, Canger EM, Sisman Y. Evaluation of root morphology and root canal configuration of premolars in the Turkish individuals using cone beam computed tomography. Eur J Dent. 2015 Oct-Dec;9(4):551-7.

38. Gu Y, Wang W, Ni L. Four-rooted permanent maxillary first and second molars in a northwestern Chinese population. Arch Oral Biol. 2015 Jun;60(6):811-7.

39. Fan B, Ye W, Xie E, Wu H, Gutmann JL. Three-dimensional morphological analysis of $\mathrm{C}$-shaped canals in mandibular first premolars in a Chinese population. Int Endod J. 2012 Nov;45(11):1035-41.

40. Naseri M, Safi Y, Akbarzadeh Baghban A, Khayat A, Eftekhar L. Survey of Anatomy and Root Canal Morphology of Maxillary First Molars Regarding Age and Gender in an Iranian Population Using Cone-Beam Computed Tomography. Iran Endod J. 2016;11(4):298-303.

41. Huang Y Der, Wu J, Sheu RJ, Chen MH, Chien DL, Huang YT, et al. Evaluation of the root and root canal systems of mandibular first premolars in northern Taiwanese patients using cone-beam computed tomography. J Formos Med Assoc. 2015 Nov;114(11):112934. 